\title{
LOS ALAMOS SCIENTIFIC LABORATORY LOS ALAMOS $\underline{\underline{\underline{\underline{\underline{\underline{1}}}}} \text { N }}$ of the MEXICO University of California
}

Evaluation Of High Explosive By Pyrolysis

UNITED STATES

ATOMIC ENERGY COMMISSION

CONTRACT W-7405-ENG. 36 


\section{DISCLAIMER}

This report was prepared as an account of work sponsored by an agency of the United States Government. Neither the United States Government nor any agency Thereof, nor any of their employees, makes any warranty, express or implied, or assumes any legal liability or responsibility for the accuracy, completeness, or usefulness of any information, apparatus, product, or process disclosed, or represents that its use would not infringe privately owned rights. Reference herein to any specific commercial product, process, or service by trade name, trademark, manufacturer, or otherwise does not necessarily constitute or imply its endorsement, recommendation, or favoring by the United States Government or any agency thereof. The views and opinions of authors expressed herein do not necessarily state or reflect those of the United States Government or any agency thereof. 


\section{DISCLAIMER}

Portions of this document may be illegible in electronic image products. Images are produced from the best available original document. 
This report was prepared as an account of Government sponsored work. Neither the United States, nor the Commission, nor any person acting on behalf of the Commission:

A. Makes any warranty or representation, expressed or implied, with respect to the accuracy, completeness, or usefulness of the information contained in this report, or that the use of any information, apparatus, method, or process disclosed in this report may not infringe privately owned rights; or

B. Assumes any liabilities with respect to the use of, or for damages resulting from the use of any information, apparatus, method, or process disclosed in this report.

As used in the above, "person acting on behalf of the Commission" includes any employee or contractor of the Commission, or employee of such contractor, to the extent that such employee or contractor of the Commission, or employee of such contractor prepares, disseminates, or provides access to, any information pursuant to his employment or contract with the Commission, or his employment with such contractor.

This report expresses the opinions of the author or authors and does not necessarily reflect the opinions or views of the Los Alamos Scientific Laboratory.

Printed in USA. Price $\$ 2.00$. Available from the

Clearinghouse for Federal Scientific

and Technical Information, National Bureau of Standards, U. S. Department of Commerce, Springfield, Virginia 


\title{
LOS ALAMOS SCIENTIFIC LABORATORY LOS ALAMOS University of California
}

\author{
Report written: Decembcr 1964
}

Report distributed: May 1965

\section{EVALUATION OF HIGH EXPLOSIVE BY PYROLYSIS.}

by

John F. Baytos 
THIS PAGE

\section{WAS INTENTIONALLY LEFT BLANK}




\begin{abstract}
It is necessary to know the thermal stability and compatibility of explosives and new explosive mixtures for safety and handling considerations. This factor can be measured by detecting the evolved gases as an explosive is heated to decomposition. This technique is known as pyrolysis gas evolution analysis (PGEA). An apparatus was built that would enable Group GMX-3 to perform these PGEA experiments on a routine basis as a complement to the other stability and compatibility tests.

The apparatus is based on the prototype developed by R. N. Rogers, Group GMX-2, and is described in detail. The various operating sequences are arranged for safety and ease of performance so that an operator's attention is given to gathering experimental data rather than to instrumentation.

A detailed experimental procedure is given in this report, and some preliminary experiments made to check the performance of this apparatus. are described. Calibration procedures are also included.

Preventive and corrective maintenance procedures are given. Illustrations and typical curves complete the report.

\section{ACKNOWLEDGEMENTS}

Grateful appreciation is extended to R. N. Rogers, who discussed this version of the apparatus and made suggestions that would substantially improve on his prototype. His work in comparing the results on the same compounds on his and our apparatus is acknowledged.

The help given by F. W. DuBois and S. V. Dubiel in discussing problems is also acknowledged. We are indebtcd to C. Lowry for the illustrations in this report. T. E. Chandler and the GMX-3 Instrumentation Unit are responsible for assembling this apparatus and keeping the electronics in operating order.
\end{abstract}




\section{CONTENTS}

ABSTRACT

ACKNOWLEDGEMENTS

1.0 INTRODUCTION

1.1 Purpose and Scope

1.2 Prototype Developed by R. N. Rogers

Page

1.3 Routine Examination of Experimental Explosives

3

1.4 Interpretation of a Typical Report

7

2.0 THE PGEA APPARATUS 7

2.1 The Pyrolysis and Detector Module $\quad$ - 7

2.1.1 The Heating Block 8

2.1.2 The Combustor $\because: \because \because{ }^{2} \quad 8$

2.1.3 The Detector and Its Environment : $\quad 8$

$\therefore$ 2.1.4 , The Helium, Vàcuum, Water, and Air System - 8

2.2 Temperature Controllers for the Pyrolysis Modules $\quad 9$

2.2.1 Temperature Programmer for the Pyrolysis Block 9 .

2.2.2 Combustor Power Regulator . 9

2.2.3 Temperature Proportional Controller for the Detector Plenum Chamber 9

2.3 Cooling Equipment and Water Demineralizer 10

2.4 Signal Transducers $\quad \ldots \cdots \cdots$

2.4.1 X-Axis Signal to Recorder $\quad 10$

2.4.1.1 Electrical Thermocouple Zero Junction 10

2.4.1.2 Ice Bath Zero Reference $\quad \cdots 10$

2.4.2. Y-Axis Signal to Recorder. . . . 10

2.4.2.1 Principle of Operation of a

2.5 Carrier Gas and Regulator $\quad 11$

2.6 X-Y Recorder, Electro Instruments (Model 500) 11

3.0 ANALYTICAL PROCEDURE 11

4.0 CALIBRATION PROCEDURES

4.1 Comparison of Pyrolysis Curves With Those Made

on the Prototype Apparatus 12

4.2 Establishment of Instrument Parameters $\quad 12$

4.2.1 Flowmeter Calibration '

4:2.2 Response of Thermal Conductivity

4.2.3 Heating Rates With Time 12

4:3,. Calibration of the X-Y Recorder Axes 13

4.3.1" Calibration of X-Axis 13

4:3.2 Calibration of the Y-Axis $\ldots . . .13$ 
5.0 MAINTENANCE AND TROUBLE SHOOTING

5.1 Manufacturers' Manuals

5.2 No Response of Meters to Temperature

5.3 Safety Overheat Relays and Indicators

5.4 Programming Longer Than Normal

5.5 Changing Demineralizer Cartridges

5.6 Irregular Erratic Readings on Water Purity Meter 14

5.7 Flowmeter Does Not Indicate Gas Flow 14

$\begin{array}{lll}6.0 & \text { REFERENCES } & 14\end{array}$

$\begin{array}{lll}7.0 & \text { APPENDIX A } & 15\end{array}$

7.1 Typical Procedure for Pyrolysis Gas Evolution Analysis 15

7.1.1 Instrument Energizing 15

7.1.2 Sample Preparation and Loading 15

7.1.3 Instrumental Check and Run 15

8.0 APPENDIX B - ILLUSTRATIONS 16

Fig.

1 Pyrolysis Gas Evolution Analysis (PGEA) Apparatus

2 Pyrolysis Module Removed from Relay Rack

3 PGEA Flow Schematic

4 Pyrolysis Block and Combustor (cross sectional diagram)

5 PGEA Electrical Schematic

6 Programmed Pyrolysis Block Temperature Versus Elapsed Time

7 Peak Heights of Different Volumes of Air and of Equal Volumes of Several Gases

8 Peak Heights of Constant Volumes of Air Injected as the Apparatus Was Being Programmed

9 Flow Rate Versus Flowmeter Setting

10 Pyrolysis Curves of HMX (99.5\% purity, United Kingdom)

11 Pyrolysis Curves of Nitroguanidine (NQ), DMF Recrystallized

12 Pyrolysis Curves of Ammonium Dichromate, $\left(\mathrm{NH}_{4}\right)_{2} \mathrm{Cr}_{2} \mathrm{O}_{7}$

13 Pyrolysis Curves of Cupric Sulfate, Pentahydrate, $\mathrm{CuSO}_{4} \cdot 5 \mathrm{H}_{2} \mathrm{O}$

14 Pyrolysis Curves of Oxalic Acid, Dihydrate, $\mathrm{C}_{2} \mathrm{H}_{2} \mathrm{O}_{4} \cdot 2 \mathrm{H}_{2} \mathrm{O}$

15 Base Line Curve

16 Pyrolysis Curve of Analytical Reference Sample of TNT

17 Pyrolysis Curve of Analytical Reference Sample of TNT Flake

16

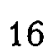

17

17

17

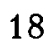

18

18

19

19

19

19

20

20

20

20

21

18 Pyrolysis Curve of Analytical Reference Sample of RDX

19 Pyrolysis Curve of Analytical Reference Sample of HMX

20 Pyrolysis Curve of Analytical Reference Sample of HMX

21 Pyrolysis Curve of Analytical Reference Sample of PETN

22 Pyrolysis Curve of Analytical Reference Sample of Cyclotol

23 Pyrolysis Curve of Analytical Reference Sample of Octol

24. Pyrolysis Curve of Analytical Reference Sample of Composition A-3

25 Pyrolysis Curve of Analytical Reference Sample of Composition B-3

26 Pyrolysis Curve of Analytical Reference Sample of Baratol

27 Pyrolysis Curve of Analytical Reference Sample of PBX 9404-03

28 Pyrolysis Curve of Analytical Reference Sample of PBX 9010-02

29 Pyrolysis Curve of Analytical Reference Sample of PBX 9011

30 Pyrolysis Curve of Analytical Reference Sample of Boracitol 
THIS PAGE

\section{WAS INTENTIONALLY \\ LEFT BLANK}




\section{I.0 INTRODUCTION}

Pyrolysis of samples to evolution of gases for detection by gas chromatography techniques is a standard method generally known as pyrolysis gas evolution analysis (PGEA). The detection of evolved gases from the pyrolysis of explosives for evaluation of stability and compatibility was first reported by R. N. Rogers and others ${ }^{1}$. His technique consists of pyrolyzing a 10-mg sample of explosive at a programmed heating rate, and sweeping away the evolved gases with helium past a thermal conductivity detector, the unbalanced signal of which is then transmitted to the $\mathrm{Y}$-axis of an $\mathrm{X}-\mathrm{Y}$ recorder. The magnitude of the signal is a measure of the quantity of gas evolved. This technique is another measure of an explosive's sensitivity and stability as a function of temperature. Information of this nature on small samples is secured at an early stage in the development of new compounds and mixtures.

1.1 Purpose and Scope - The purpose of this report is to record the development of this automated apparatus and to record typical curves obtained from reference samples of explosive compounds and mixtures in current use at GMX-3.

The scope will include the description of the apparatus, some of the problems that were solved in assembling it, the experimental procedure, calibrating procedures, and maintenance instructions for this unit.

1.2 Prototype Developed by $R$. N. Rogers - The apparatus is based on the prototype developed by Rogers, as reported in his paper "Pyrolysis as an Analytical Tool"1. At Rogers' suggestion, a thermistor detector was substituted for the hot-wire filament detector. The result was an instrument with improved sensitivity. The components used were generally commercially available. Convenience features such as solenoid operated valves were added as needed, but the principle of the experimernt was not changed.

The curves generated by using this instrument and Rogers' prototype instrument show good agreement. The curves for several explosives are shown in Figures 10 and 11. Samples containing water of hydration, Figures 13 and 14, do not compare precisely. (All figures will be found in Appendix B.)

1.3 Routine Examination of Experimental Explosives - Routine determination of the thermal stability of experimental and production samples of explosives used in GMX-3 operations is required by the Standing Operating Procedures. The PGEA tests are complementary to those of vacuum thermal stability (VTS), differential thermal analysis (DTA), and the Livermore chemical reactivity test (LCRT). LCRT is a thermal stability test followed by gas chromatography of the evolved gases. The pyrolysis apparatus was designed and built to generate the PGEA information routinely with ease and safety.

1.4 Interpretation of a Typical Report - Figures 16 through 30 show typical curves given by reference samples of explosive compounds and mixtures. As long as there is no change in the compound, the trace will follow a base line (Figure 15). If there is moisture, a small hump will appear around $100^{\circ} \mathrm{C}$. Solvates will appear at their respective temperatures of separation. Occluded gases or vapors appear whenever they burst their confinement, and usually produce small peaks. When materials decompose rapidly at their explosive or autocatalytic temperature, the trace will go off scale.

The appearance of a decomposition peak at a lower temperature than that shown in the reference charts is interpreted as an indication of lowered thermal stability for that particular sample.

\subsection{THE PGEA APPARATUS}

The PGEA apparatus, Figure 1, consists of modular components assembled in a relay rack with all controls arranged for operational convenience. A helium tank and regulator and an $\mathrm{X}-\mathrm{Y}$ recorder which is separate from the relay rack complete the arrangement.

The heart of the apparatus is the pyrolysis module, Figure 2, which is mounted at a working height in the relay rack on a slide chassis for easy dismantling and servicing. The sample entry port, switches, valves, flowmeters, pilot lights, and controls for operation of the module are located on the front panel. The utilities, power, signals, coolant, and waste disposal connections are located on the back and are equipped with fittings that are easily disconnected.

The other panels on the relay rack hold the accessory equipment to make the pyrolysis module function. The temperature programmer, the combustor temperature regulator, and the detector module temperature controller components are mounted below the pyrolysis module. Meters indicating temperatures of the pyrolysis, combustor, and detector units are located across the top panel. The bridge for the thermistor detector and its power supply and the electronic zero reference for the block temperature complete the components mounted on the relay rack. A water demineralizer is mounted inside to furnish deionized water for cooling the pyrolysis block on completion of a run.

2.1 The Pyrolysis and Detector Module - Since the complete process of pyrolysis, combustion of effluent gases, and detection, takes place in sequence, the essential elements for this operation were mounted on a chassis module as shown in Figure 2 and on the flow 
sheet, Figure 3. On this chassis were mounted also the solenoid valves and their interlocking switches, fine metering valves, a flowmeter, and quick-disconnect couplings for the utilities.

2.1.1. The Heating Block - The pyrolysis blōck, shown in cross section in Figure 4, is a stainless steel cylinder 4 inches in diameter by 4 inches long. This block has been bored to permit a sweep of helium through the center and over the sample. The sample is inserted through the front port. Two 5/8-inch wells on either side of the center bore will accept cartridge heaters (Firerods, 1100 watts, LA-168, Watlow Manufacturing Company, St. Louis). Three $1 / 8$-inch wells accept ceramic sheathed thermocouples for temperature control and indication. The tips of the thermocouples are located underneath the sample location to give as reliable a temperature indication as possible. A spiral groove on the outside wall accepts deionized water for cooling and compressed air for purging. The condensate line is connected to a drain by wire-braided high-pressure hose. For reasons of safety, the hose is securely fitted to the drain inlet with a standard pipe union. The block is bolted to a transite box with only the breech-loading sample:port showing on the outside of the panel. The breech consists of a plugg, held in place by an Acme threaded screw for quick, tight, and safe opening and closing. During heating, the entry port is covered by the insulated sliding door.

2.1.2 The Combustor - The combustor is shown in cross section in Figure 4 . It is a $1 / 4$ inch-OD stainless steel tube packed with an $80 / 20$ by weight mixture of copper.oxide filings and chopped quartz crystals of 250- to 350microns diameter. Quartz wool plugs are used as stoppers on each end of the combustor tube. This tube is connected to the helium egress side of the pyrolysis block with a Swagelok fitting, and is mounted in the same transite box with the pyrolysis block (Figure 2).

The combustor tube is heated by a single cartridge heater which is attached to the tube by means of a hose clamp. Two thermocouples are mounted on top of the tube; one indicates temperature and the other operates a safety shut off relay if the temperature goes over $675^{\circ} \mathrm{C}$. Power to the heater is manually controlled by a Powerstat adjusted to give a minimum temperature of $600^{\circ} \mathrm{C}$.

When the sample decomposes, the gases are swept by the helium through the combustor where the effluent gases are oxidized, to $\mathrm{CO}_{2}$, $\mathrm{H}_{2} \mathrm{O}$, and $\mathrm{N}_{2}$ by the copper oxide filings. The copper filings are reactivated between sample runs. by drawing air through the tube. This function is controlled from the front panel by the helium-air switch for the solenoid valves.

After the samples are oxidized, the gas is swept from the combustor through 1/8-inchOD stainless steel tubing into the detector block in the adjacent compartment.

\subsubsection{The Detector and Its Environment -} The detector unit is a thermal conductivity cell (Gow-Mac Company, Model AEL-9677). It uses 8000 -ohm matched thermistors in the sample detector and in the reference streams. These two thermistors constitute two legs of a Wheatstone bridge. The remaining two legs of the bridge, the power source for the bridge, and the zero and sensitivity controls for the bridge are provided by a Gow-Mac Company Model 9999 D: 1-1 control unit. The detector cell has an internal volume of $1.7 \mathrm{~cm}^{3}$ and is designed for a gas flow of $50 \mathrm{~cm}^{3} / \mathrm{min}$.

The detector cell is maintained at a constant temperature of $50^{\circ} \mathrm{C}$ in a circulating air plenum chamber (Figure 2). The helium reference stream and the sample gas mixture are conditioned to $50^{\circ} \mathrm{C}$ by coils made up of 72 inches of $1 / 8$-inch $\mathrm{D}$ tubing.

Heating is provided by Nichrome wires attached to porcelain insulators on one side of the chamber. A squirrel cage blower is mounted on this side, and the heater wires are shielded from the chamber by a baffle. Air from the chamber is drawn through the center opening, blown over the heating elements, and forced. back into the plenum chamber. It is claimed that this system gives increased uniformity of temperature throughout the chamber ${ }^{2}$.

Power to the heaters is regulated by a silicon controlled rectifier (SCR) unit monitored by a thermistor sensor, and is described below. under temperature controllers.

2.1.4. The Helium, Vacuum, Water, and Air System - These four utilities are coupled to the chassis with Swagelok double-end shutoff quick-disconnecting couplings.

The carrier gas stream is shown in the flow sheet, Figure 3. Helium enters the system at the Swagelok double-end shutoff coupling, passes through the solenoid valve $A$, through the metering valves, through the reference side 
of the detector, into the pyrolysis block to pick up any effluent gas from the sample, through the combustor, to the sample side of the detector, and out by way of the calibrated flowmeter.

Provision has been made to trap gases evolved at any temperature in a U-tube cooled by liquid nitrogen. This trapped sample can then be analyzed by other means such as GC, IR, or mass spectrometry.

In the interim between experiments, the copper oxide in the combustor is regenerated by drawing air through the combustor. This is accomplished by means of the helium-oxidize switch which actuates solenoid valves $A$ and $B$. Placing the switch in the oxidize position shuts off valve $A$ and opens valve $B$ to $a$ vacuum line to draw air through the combustor.

At the completion of an analysis, the water-air switch controlling solenoid $\mathrm{C}$ is actuated and deionized water is metered into the hot pyrolysis block.

When the block returns to room temperature, the switch controlling solenoid $\mathrm{D}$ is activated and the block is purged of water by compressed air. Before another analysis is run, the water-air switch is returned to neutral to close both air and water valves $C$ and $D$.

2.2 Temperature Controllers for the Pyrolysis Modules - There are three separate heating systems in the pyrolysis module. Each is controlled by its own power supply and regulators.

\subsubsection{Temperature Programmer for the} Pyrolysis Block - Power is regulated to the pyrolysis block cartridge heaters from a motordriven Powerstat in an open loop system. Since a fixed rate of temperature rise $\left(12^{\circ} \mathrm{C} / \mathrm{min}\right)$ is considered adequate for these experiments, the motor-driven Powerstat as used in the DTA apparatus ${ }^{3}$ is used. A motor drives the 20 -amp Powerstat at $0.6 \mathrm{rph}$ and the voltage is advanced from 38 to 75 volts. This gives an approximately linear temperature rise of $12^{\circ} \mathrm{C} / \mathrm{min}$ in the pyrolysis block. The power to the heaters is activated through a mercury relay switch at the start of a program. At the end of the program, a limit switch shuts off the mercury relay and activates a buzzer. Should there be a failure in the shutoff, and the block go beyond its final program temperature, a thermocouple-activated interlocking safety relay switch will open the mercury relay and break the circuil to the heaters. When this happens, the safety relay must be reset manually to put the unit back into operation. The slider of the Powerstat is returned to the initial point manually by releasing a friction clutch which is included in the gear train. Pilot lights on the front of the panel show the program as "on", "end", or "overheat". The schematic of this circuit is shown in Figure 5.

The power line from the programmer to the pyrolysis module can be disconnected and other temperature programmers substituted. Extra thermocouples in the block are available for closed loop control, should other programmers be used for temperature program rates other than the fixed rate.

The time-temperature curves for this and other programmers are shown in Figure 6.

2.2.2 Combustor Power Regulator - Since the combustor is maintained between 600 and $650^{\circ} \mathrm{C}$, an elaborate controller is not used for this unit. The power is supplied through a Powerstat which can handle 10 amp maximum current, and is adjusted to deliver only enough current to maintain the temperature at a minimum of $600^{\circ} \mathrm{C}$. The influence of the hot pyrolysis block causes the temperature of the combustor to go somewhat higher. A thermocouple-activated interlock safety relay switch will shut off current to the heater, should the temperature rise to $675^{\circ} \mathrm{C}$. This relay is a duplicate of the safety relay shown on the program circuit in the schematic (Figure 5).

\subsubsection{Temperature Proportional Controller} for the Detector Plenum Chamber - Power to the plenum chamber heaters is proportionally controlled by a regulated silicon controlled rectifier (SCR) in a closed loop system (Dynatronics Instrument Corporation, Dyna-Pac-10 8102). The thermistor in the chamber senses any temperature change by changing its resistance. This transducer signial is picked up by the preamplifier which acts as a variable resistance. The preamplifier changes the resistance-capacitance ( $R C$ ) time constant of the circuit. When the firing voltage of the transistor is reached, a pulse is formed which triggers the SCR. The RC timing is the proportioning time to the firing voltage which regulates the current to the heaters. Control adjustments on the unit permit close temperature control, and the chamber is maintained at $50+0.05^{\circ} \mathrm{C}$. 


\subsection{Cooling Equipment and Water Demineralizer -}

To bring the apparatus back to room temperature quickly after an experiment has been completed, the pyrolysis block is cooled by introducing demineralized water into the block which is at $500^{\circ} \mathrm{C}$. At this temperature, water is vaporized immediately, and any minerals in the water would deposit out as a scale and reduce cooling efficiency. To prevent scale buildup, demineralized water is used for cooling ${ }^{4}$.

A Bantam twin demineralizer pressure type cartridge holder containing a mixed resin cartridge and an organic removal cartridge is mounted in the relay rack. Water that has been run through each cartridge in series is of sufficient purity to cool the block without leaving harmful deposits. The condensate and steam are disposed of by running them into a drain through a wire-braided high-pressure steam hose. The purity of the water is sensed by conductivity electrodes located in the water stream. When the resistance of the treated water drops to $200,000 \mathrm{ohms}$, the mixed resin cartridge is replaced.

About 5 gallons of demineralized water are required to cool the block from $500^{\circ} \mathrm{C}$ to room temperature. The block cools in $20 \mathrm{~min}$. Cooling is more efficient when the water is run through slowly.

When the pyrolysis block is at room temperature, it is purged of water by compressed air which is turned on by a solenoid valve controlled by an interlocking switch on the front panel. When the water has been removed, the water and air solenoid valves are closed and the apparatus is ready for another run.

2.4 Signal Transducers - The signal for recording the pyrolysis block temperature comes from a thermocouple located $1 / 4$ inch below the sample boat in the block (Figure 4). The thermal conductivity response signal comes from the detector thermistors. These are described in detail below.

Thermocouples for signals to meters on the front panel to indicate the temperature of the heating systems in the pyrolysis module, signals to the temperature overshoot relays, and signals for feedback to a temperature programmer are shown schematically in Figure 5. All thermocouples are brought to a receptacle at the rear of the pyrolysis module for quick disconnection.

2.4.1 $X$-Axis Signal to Recorder - The Xaxis signal, the temperature of reaction, generated by a Chromel-alumel thermocouple in the pyrolysis block (Figure 4) referenced to a Con-Ohmic electronic zero reference (Model JR114A, Consolidated Ohmics Inc., New Hyde- Park, N.. Y.) is led through a low resistance switch to a jack on the panel. From here the signal is picked up and run into the X-Y recorder at the $\mathrm{X}$-input as shown in Figure 5.

\subsubsection{Electrical Thermocouple. Zero} Junction-The zero thermocouple reference junction is a self-contained, self-powered, passive state electric equivalent of an ice bath.

The thermocouple measuring circuit is wired in the usual way. The output then indicates the millivolts generated by the difference in the temperature of the test and ambient reference thermocouple. To compensate for the difference in millivolt output between ambient temperature and $0^{\circ} \mathrm{C}$, an additional voltage is impressed on the input side of the recorder. This additional voltage is provided by the output of a Wheatstone bridge, one leg of which is a temperature sensitive resistor, adjusted to vary its resistance in proportion to differences in ambient temperature, to provide the correct voltage supplement so that the circuit will have a zero reference over a wide ambient temperature range.

\subsubsection{Ice Bath Zero Reference - An ice} bath can be substituted directly for the electric zero reference if necessary.

2.4.2 Y-Axis Signal to Recorder - The Y-axis signal is the output of the unbalance of a Wheatstone bridge caused by a thermistor located in the sample side of the thermal conductivity cell and a reference thermistor located in the carrier gas side of the cell.

The power supply and bridge control for the high resistance and low current thermistors is Gow Mac Company's Model 9999D:1-1. The power supply includes a voltage regulating transformer and Zener diode reference to improve signal to noise ratios, to avoid zero drift, and to stabilize output over a large ambient temperature range. The current to the thermistor bridge is adjusted to $10 \mathrm{ma}$ for these thermistors. The zero and sensitivity controls adjust the output to match the zero and span of the $\mathrm{Y}$-axis of the recorder. The attenuation of the signal is continuous. There is sufficient gain available to allow small peaks to be expanded by a factor of 100 over their height in a normal run.

\subsubsection{Principle of Operation of $a$} Thermal Conductivity Cell - In a thermal conductivity cell, the heat loss of a thermistor to a carrier gas in the reference stream is compared with that of a matched thermistor to a mixture of the carrier gas and some other effluent or contaminant gas in the sample stream. The thermistors are installed coaxially in identical cavities in the detector cell and are matched with respect to ohmic resistance and negative coefficients of resistance. 
With a constant DC current of $10 \mathrm{ma}$ flowing through the thermistors, they assume a constant temperature and lose their heat equally and in all directions. This results in identical thermistor temperatures and resistances, giving a balanced bridge and a null signal.

The helium carrier gas has a high thermal conductivity, and most gases, except hydrogen, have lower thermal conductivities. A gas contaminant or effluent of lower thermal conductivity in the sample stream will allow that thermistor to assume a higher temperature and the resulting lower resistance will unbalance the bridge. The unbalance of the bridge is in proportion to the quantity of gas contaminating the helium carrier stream.

The output of the bridge is then impressed on the Y-axis of the X-Y recordcr and measured as a thermal conductivity response in millivolts. This response can be calibrated for known gases.

The calibration of the recorder and bridge to each other is done by adjusting zero at one end of the scale with helium in both passages, and then adding measured volumes of known gases from a hypodermic gas syringe into the sample entry port. The deflections of various sample sizes of different gases are given in Figure 7 . These values were obtained under constant conditions of 1) thermistor current (10 ma) and temperature, 2) temperature of detector cell $\left.\left(50^{\circ} \mathrm{C}\right), 3\right)$ gas pressure $(20 \mathrm{psig})$, and 4) flow rate $(50 \mathrm{ml} / \mathrm{min})$.

Since the effluent gases in pyrolysis experiments are mixtures of several gases, the peaks on programmed curves represent the sum of all gases present.

2.5 Carrier Gas and Regulator - The carrier gas for routine experiments is helium as supplied commercially in gas cylinders. The regulator is a commercially available Victor VTS202.

\subsection{X-Y Recorder, Electro Instruments (Model} 500 ) - Thermal conductivity response is recorded as a function of temperature on an Electro-Instruments, Inc., Model $500 \mathrm{X}-\mathrm{Y}$ recorder. The Model 500 is a two-axis, flat bed, general purpose graphic recorder that accommodates up to $11-\mathrm{x} 17$-inch graph paper.

Each axis of the recorder is controlled by an identical self-balancing servomechanism, electrically independent and isolated from ground. The input circuits are all-solid-state with Zener diode voltage reference and provide 1 megohm input impedance. The voltage spans of the $\mathrm{X}$ and $\mathrm{Y}$ axes can be set to multiples of 1 , 2,5 , and $10 \mathrm{mv} / \mathrm{inch}$ on each scale with scale multipliers to $10^{4}$. The $\mathrm{X}$-axis can be switched to a time mode of rates from $12.5 \mathrm{~min}$ to $15 \mathrm{sec}$ per full span.

The $\mathrm{X}$ and $\mathrm{Y}$ voltage spans can be set to other than the fixed values by a vernier adjustment between adjacent span settings, with the ability to extend the sensitivity to $0.5 \mathrm{mv} /$ inch on the most sensitive scale setting. This feature is valuable in this experiment because the millivolt output can be adjusted to compress or expand the graph scales within the accuracy of the instrument. The $\mathrm{X}$ and $\mathrm{Y}$ zeros can be set at any point on the graph up to $90 \%$ offset to full scale. These features allow one to read the X-Y information in terms of temperature or other variables, for direct interpretation and comparison with data already published.

\subsection{ANALYTICAL PROCEDURE}

After the apparatus has been turned on and the experimental conditions stabilized, a $10-\mathrm{mg}$ sample of explosive weighed into a platinum or aluminum combustion boat is inserted at the breech opening. The opening is sealed by a soft copper washer and the plug is held in place by the breech arm and screw. The rate of helium flow is adjusted, the $\mathrm{X}$ and $\mathrm{Y}$ axis signals are adjusted to starting conditions, and the temperature programmer is started. No further adjustments are needed until the experiment is completed $45 \mathrm{~min}$ later. The decomposition of the sample will generate gases which will be swept past the thermal conductivity detector by the carrier gas helium and be indicated as peaks on the graph paper. At the end of the experiment, the heater will shut off automatically and a buzzer will sound. The apparatus is then cooled to return it to the starting condition for another experiment.

A typical step-by-step procedure developed for use at Group GMX-3 is given in Appendix A.

\subsection{CALIBRATION PROCEDURES}

The variables of heating rates, gas flow rates, sensitivity response of the thermistor thermal conductivity detector, sample weights, pressures, and carrier gases have been reported adequately by Rogers et al. in their paper $^{1}$. Since this apparatus was designed to obtain pyrolysis curves on explosives routinely, the calibration procedures perfurmed were only those necessary to match the shape of curves already recorded. Several tests were performed to establish some parameters on conditions for this instrument: 1) the flowmeter for different gases was checked against a wet test meter, 2) the response of the thermal conductivity detector to measured quantities of gases in the helium stream was determined, and 3) the heating rate produced by the temperature programmer was established. 
'For 'routine operations, a quick calibration' procedure for the $\mathrm{X}$ and $\mathrm{Y}$ axes on the recorder is described in Section 4.3.+

4.1 Comparison of Pyrolysis Curves With Those Made on the Prototype Apparatus - Five different chemicals having sharply defined decomposition temperatures were used as common samples to compare pyrolysis curves produced by each apparatus. The compounds are 1) HMX, 99.5\%, UK, 2) nitroguanidine, 3) ammonium dichromate, 4 cupric sulfate, pentahydrate, and 5) oxalic acid, dihydrate.

The apparatus was adjusted and determinations were repeated on each of the five compounds until curves were produced that resembled those of Group GMX-2 published data. The HMX compound gave the most sharply defined peak and was chosen for setting the instrument conditions so that data from each apparatus could be interchangeable. The other four curves were then run without any further adjustment of the GMX-3 apparatus.

These five samples were used by Rogers to produce pyrolysis curves on his apparatus. The curves from each apparatus; superimposed on each other, are shown in Figures 10 through 14, with appropriate comments in the captions.

Data from either apparatus are considered reliable and interchangeable.

\subsection{Establishment of Instrument Parameters}

4.2.1 Flowmeter Calibration - A wet test meter was attached to the exit side of the pyrolysis gas stream, and carrier gases were initroduced at the input side. The combustor and detector cells were at operating temperature, while the pyrolysis block was at room temperature. The flowmeter ball indicator was adjusted to various heights with the metering valves, and the regulator on the gas cylinder was held constant at 20 psi. The gases were run through the apparatus for $3 \mathrm{~min}$ for each setting. Figure 9 shows the curves of volume per minute versus flowmeter height for helium, nitrogen, air, and carbon dioxide.

When helium is used as the carrier gas, adjustment of the ball indicator to $6 \mathrm{~cm}$ in the flowmeter will allow passage of $50 \mathrm{ml} / \mathrm{min}$. This is the rate for routine experiments.

\subsubsection{Response of Thermal Conductivity} Thermistor to Various Gases - To determine how sensitive the thermistor is to different gases, the apparatus was set up as for a conventional run at the start of an experiment. A hollow piug holding a sealing septưm was inserted into the breech opening so that a measured quantity of gas could be introduced from a calibrated gas syringe. Conditions of temperature, flow, pressure, and current were held constant.

The peak heights for air (Figure 7) show that the response is linear for multiple quantities. The peak heights for equal volumes of other gases are proportional to their thermal conductivities.

The sensitivity of the instrument is defined as the relationship between the minimum change in the peak height and the magnitude of change in measured quantity required to produce that minimum change. The thermistorrecorder system under these constant conditions will show that 2.2 microliters of air are detected per $1 \mathrm{~mm}$ change in peak height:

Another experiment was run in the program mode. At every $40^{\circ} \mathrm{C}$ increase in the block temperature, a 250-microliter sample of air was injected into the block. The peaks resulting from the air samples at these temperatures are shown in Figure 8. This shows that the gases are equilibrated for measuring at $50^{\circ} \mathrm{C}$ and are not sensitive to the temperature of the combustor or pyrolysis block.

4.2.3 Heating Rates With Time - To check the rate of heating of the pyrolysis block, a thermocouple from the block was attached to a strip chart recorder and checked with the $\mathrm{X}$-axis temperature scale on the $\mathrm{X}-\mathrm{Y}$ recorder. The motor-driven Powerstat was driven at $0.6 \mathrm{rph}$ from 38 to 75 volts. The temperature versus time relationship is shown in Figure 6, Curve B. The rate of rise for these settings is approximately $12^{\circ} \mathrm{C} / \mathrm{min}$.

To run the apparatus at other than the fixed rate, provision has been made to substitute a linear temperature programmer. A feedback thermocouple outlet is available for closed loop control in the system. A programmer can operate a relay and turn the cartridge heaters on and off in the pyrolysis block. The curves of various heating rates, 6, 12, and $21^{\circ} \mathrm{C} / \mathrm{min}$, with this system are also shown in Figure 6, and are generally linear except at the start.

It is possible to hold the pyrolysis block at any desired temperature. A U-tube immersed in liquid nitrogen at the exit side of the apparatus will capture effluent fractions 
which can be transferred to other instruments such as a gas chromatograph or mass spectrometer for further studies.

4.3 Calibration of the X-Y Recorder Axes - The X and $\mathrm{Y}$ axes are calibrated using the HMX decomposition peak as the primary standard. When this peak occurs at $262 \pm 1^{\circ} \mathrm{C}$ and gives a full scale height reading for a 10-mg sample, the instrument is calibrated with respect to temperature and sensitivity. When this is accomplished, similar peaks will be generated on comparable instruments as shown in Figures 10, 11, and 12.

\subsubsection{Calibration of $X$-Axis - An approxi-} mate calibration is made with a voltage source as the standard. The voltage source is connected to the $\mathrm{X}$-axis input of the recorder. With zero volts impressed across the input, the carriage of the recorder is set by the zero knob to indicate $0^{\circ} \mathrm{C}$ on the graph paper. With 14.70 volts, the millivolt equivalent for Chromelalumel thermocouples for $360^{\circ} \mathrm{C}$, impressed across the input, the carriage is adjusted to indicate $360^{\circ}$ on the graph paper by using the variable scale adjustment knob.

The final calibration is made using the decomposition temperature of UK 99.5\% purity HMX as the primary standard. A test run is made with this HMX as the sample material. If the decomposition peak does not occur at $262 \pm 1^{\circ} \mathrm{C}$, the equation below can be used to adjust the span to record the correct gas evolution temperature.

$$
\mathrm{C}=\frac{\mathrm{A} \times \mathrm{B}}{\mathrm{D}}
$$

where: $C$ is the correct span in millivolts,

$A$ is the initial millivolts (14.70) impressed on the $\mathrm{X}$-axis for the calibration run,

$B$ is the indicated gas evolution temperature from the calibration run, and

$\mathrm{D}$ is the correct gas evolution temperature (HMX) standard used is $262^{\circ} \mathrm{C}$ ).

The corrected span voltage is then impressed on the $\mathrm{X}$-axis from the voltage source as before. The zero and variable scale knobs are readjusted to record the correct span. Running another HMX test curve will verify the alignment of the gas evolution peak with the $262^{\circ} \mathrm{C}$ mark on the graph. The curve should be identical with that shown in Figure 10.

\subsubsection{Calibration of the $Y$-Axis - The Y-}

axis span of the recorder is set to a fixed value of $10 \mathrm{mv}$ by using the scale and scale multiplier switches. The variable scale knob of the recorder is locked in the full counterclockwise position.

The sensitivity knob on the Gow-Mac control unit is set to 0.20 and the zero knob to 4.80 . The pen on the recorder should indicate zero.

A 10-mg sample of HMX is run in the usual way. The HMX peak should rise to the maximum height on the chart and immediately return downward without dwelling. If the peak is not at full scale height, the sensitivity control on the Gow-Mac control unit is adjusted either upward or downward, according to the equation

$$
C=\frac{A \times B}{D}
$$

where: $C$ is the correct sensitivity setting on the control unit,

$A$ is the initial sensitivity setting on the control unit for a calibration run,

$\mathrm{B}$ is the measured height in millimeters of the gas peak, and

$\mathrm{D}$ is the correct height desired in millimeters (HMX standard is 250 $\mathrm{mm}$ ).

A repeat run on HMX will verify the height of the peak at the same time as the $\mathrm{X}$ axis temperature calibration is made. The height and shape of the curve should be identical with that shown in Figure 10.

The fixed span settings on the $\mathrm{Y}$-axis of the recorder, and the sensitivity setting on the control unit can be set to multiples of the calibration settings without changing the slope of the curves. In some cases this gives improved signal to noise ratios.

\subsection{MAINTENANCE AND TROUBLE SHOOTING}

5.1 Manufacturers' Manuals - Maintenance of the electronic components of the Electro Instrument Model $500 \mathrm{X}-\mathrm{Y}$ recorder, the Gow-Mac Bridge and Power Supply, the Consolidated Ohmics Zero Reference, the Dyna-Pac 10 temperature controller, and the Barnstead Twin-Demineralizer B-D-22 are adequately covered by the service manuals ${ }^{5-9}$ that are supplied with the instruments. Any trouble with these instruments can be referred to instrument technicians. 
-... :5:2 No Response of Meters to Temperature - The three meters indicate the temperature of the 1) pyrolysis block, 2) combustor, and 3) detector plenum chamber. If all controls are on and the meters are not responding, check for broken thermocouples. At each location, there is an extra pair of thermocouples. Interchange jacks on the back panel until there is a registration, or look for trouble in the meter movement, circuit continuity, faulty temperature controllers, blown fuses, and burmed out heaters. The burned out heaters can be replaced by removing and dismantling the pyrolysis module from the rack.

5.3 Safety Overheat Relays and Indicators - When the pyrolysis block or the combustor overheats, as indicated by the meter needle indicating in the red zone, a thermocouple signal will activate the safety relay which will close and shut off power to the heaters and turn the overheat indicating lamp on.

The safety relay must be manually reset after the temperature has dropped to a level below the cutoff upper limit. At the same time, look for malfunction of mechanical gear in the programmer, and/or adjust the combustor. Powerstat to a lower level.

5.4 Programming Longer Than Normal - If the completion of a program. takes much longer than 45 min., check for burned cartridge heaters in the pyrolysis block. With all power off, check continuity and resistance with a meter at the power terminal strip on the bottom of the pyrolysis module chassis. The cartridge heaters have a nominal value of $11 \mathrm{ohms}$ and higher resistances lower the heating rate. If continuity of the heater is broken, or if the resistance is changed to a much higher value than $11 \mathrm{ohms}$, remove the module from the chassis and replace the heaters in pairs.

If the program takes only several minutes longer than $45 \mathrm{~min}$, look for loose knobs on the Powerstat shaft, which will result in improper start and stop settings. Check the gear train and clutch drive mechanisms. The starting voltage is 38 and the maximum voltage is 75 for these routine experiments, and the Powerstat start and stop settings should be made to correspond.

5.5 Changing Demineralizer Cartridges - When the water purity meter indicates 200,000 ohms resistance, replace the mixed resin cartridge in the demineralizer barrel. The gasket should seal with only finger tightening. Shut off the water, depressurize the system, turn off the power to the solenoids and the water purity bridge, and remove the cartridge holder from the cover.

The cartridge for removal of organic materials is replaced every third time the mixed resin cartridge is replaced.

5.6 Irregular Erratic Readings on Water Purity Meter : The water meter indicates the condition of the demineralized water used for cooling. purposes. When the water conductivity cell is operating correctly, the resistance of the water will be indicated correctly according to the calibration. The mixed resin cartridge is replaced at a reading of less than 200,000 ohms.

If the meter needle oscillates wildly, it is likely that the electrodes are contaminated by particles of resin that have separated from the cartridge. Shut off the power to the purity bridge and meter, depressurize the water system, and remove the conductivity cell electrodes for cleaning.

The electrodes are cleaned electrolytically in HCL (10\%) according to Beckman Method $726^{10}$. A graphite rod in the solution is attached to the positive 22 - volt terminal of a battery. The electrodes of the cell are placed in the solution and attached to the negative terminal of the battery. This cleaning process takes only $30 \mathrm{sec}$. The electrodes are removed from the acid, washed with distilled water, and replaced in the demineralizer. When the system is put back in operation, the reading should be correct.

5.7 Flowmeter Does Not Indicate Gas Flow - If the ball indicator in the flowmeter does not rise, the usual trouble is a leak at the breech opening. Replace the soft copper gasket. It may be necessary to ream out the old gasket. Coat the new gasket with approximately a 50/50 by volume mixture of graphite and Silver Goop (proprietary product of the Crawford Fitting Company.). Reinsert the plug and breech screw. If the system is not sealed, the plug should be removed and cleaned with fine emery paper and then coated lightly with the graphite-Silver Goop. This usually will stop the leakage, and a correct flow of helium carrier gas will be indicated on the flowmeter. Also check leakage and action of the solenoid valves and their corresponding electrical switches.

\subsection{REFERENCES}

1. Rogers, R. N., Yasuda, S. K., and Zinn, John, "Pyrolysis as an Analytical Tool", Analytical Chemistry, (32) 672, May 1960 (LADC3989)

2. Peterson, R. D. "Design and Evaluation of Programmable Baths for Gas Chromatography", Journal of Gas Chromatography, (1) 19-23, December 1963

3. Dubiel, S. V." and Baytos, John F., "The Differential Thermal Analysis Unit at Group GMX-3", Los Alamos Scientific Laboratory Report LAMS-2988, December 24, 1963

4. Penfield Manufacturing Co., Inc., "Demineralized Water Helps Jets off the Run- 
way", Water Works Engineering, March 1960

5. Electro-Instruments, Inc., "Model $500 \mathrm{X}-\mathrm{Y}$ Recorder Instruction Manual", Publication 15-012, San Diego, California, 1963

6. Gow-Mac Instrument Co., "Operating Instructions, Gow-Mac Regulated DC Power Supply 9999 D-1:1", Madison, New Jersey, 1962

7. Consolidated Ohmic Devices, Inc., "Solid State Thermocouple Reference Junctions", Publication CO-762-1, New Hyde Park, New York, 1962

8. Dynatronics Instruments Corporation, "Instruction Manual for Dyna-Pac 10 Proportional Temperature Controller", Chicago, Illinois, 1962

9. Barnstead Still \& Sterilizer Company, "Installation and Operating Instructions for Barnstead Model BD-22, Double Cartridge IIolder, Pressure Type", Boston, Massachusetts, 1962

10. Beckman Instruments Incorporated, "General Instructions on 326 Metallic Electrodes", Bulletin 726, Fullerton, California, 1960

\subsection{APPENDIX A}

7.1 Typical Procedure for Pyrolysis Gas Evolution Analysis

\subsubsection{Instrument Energizing}

1. Attach the quick-disconnect couplings for the helium, air, vacuum, and water to the apparatus and turn the utilities on. Adjust the needle valve on the demineraltizer to $1 / 4$ turn.

2. Adjust the helium cylinder regulator to 20 psi.

3. Turn on the power to the pyrolysis module, to the Dyna-Pac controller, and to the combustor heater. The combustor heater takes about 2 hours to reach a temperature of 600 to $650^{\circ} \mathrm{C}$.

4. Turn the helium solenoid on. Adjust the flow to 6-cm height. Turn electrical zero reference on.

5. Turn the current knob on the Gow-Mac Bridge Control Unit full CCW before turning the power switch on. After the power is on, with helium flowing, adjust the current to 10 ma with the coarse and fine knobs.

6. Reset the programming Powerstat to 38 volts.

7. Turn the Model $500 \mathrm{X}-\mathrm{Y}$ recorder on, and set the function switch to Standby.

\subsubsection{Sample Preparation and Loading}

1. Weigh $10 \mathrm{mg}$ of the sample into a platinum combustion boat (Coleman disposable aluminum boats can be substituted if sample does not react with aluminum).

2. Use special tools provided to open the breech screw and retract the plug (use care as these may be hot).

3. Remove the boat from the previous run.

4. Use tweezers to load the boat into the 1/4-inch opening. Push the boat in about $1 / 4$ to $1 / 2$ inch beyond the opening.

5. Coat the plug lightly with the graphiteSilver Goop mixture on a chamois skin.

6. Insert the plug and seal the breech by using the special tool. Check for complete sealing. The flowmeter will not register if there is a leak.

7. Draw up the insulator shield over the breech opening.

\subsubsection{Instrumental Check and Run}

1. Adjust the helium flow indicator to a reading of $6 \mathrm{~cm}$ on the flowmeter by using the fine metering valve knob.

2. Turn the $\mathrm{X}-\mathrm{Y}$ recorder to On. Plug the jack shorting jumper into the $\mathrm{X}$-axis and adjust the carriage to read zero on the graph paper. Remove the shorting jack.

3. Turn the $\mathrm{X}$-axis switch on. The pen will shift to record the temperature of the pyrolysis block.

4. Plug the jack shorting jumper in the Yaxis input and adjust the pen to read zero on the graph paper. Remove the shorting jack.

5. Turn the Y-axis switch on. The pen will shift very slightly. Turn the function switch to Record (pen goes down to write).

6. Turn the water/air switch to Off. 
7. Check the program Powerstat setting to start at 38 volts.

8. Turn the program switch on.

9. Let the automatic programmer advance through $450^{\circ} \mathrm{C}$, at which temperature it will cut off the power to the heaters.

10. At the end of the run, when the buzzer sounds, the heater lights go out and the finish light comes on. Turn the recorder function switch to Standby.

11. Turn the program switch to Off.

12. Turn the helium/oxidizer switch to Oxidize.

13. Turn the water/air switch to Water. (Cool water will turn to steam instantly and will be drawn off to a drain through the high-pressure safety hose. After 10 min., the temperature drops to about $100^{\circ} \mathrm{C}$. It takes another $10 \mathrm{~min}$ to drop to room temperature.).

14. When the pyrolysis pyrometer shows the block to be at room temperature, turn the water/air switch to Air to purge the block of residual water.

15. Reset the program Powerstat to 38 volts.

16. Turn the helium/air switch back to Helium, and the water/air switch to Off. The instrument is ready for another run.

17. Record the sample identification and supporting data on the graph paper.

\subsection{APPENDIX B - ILLUSTRATIONS}

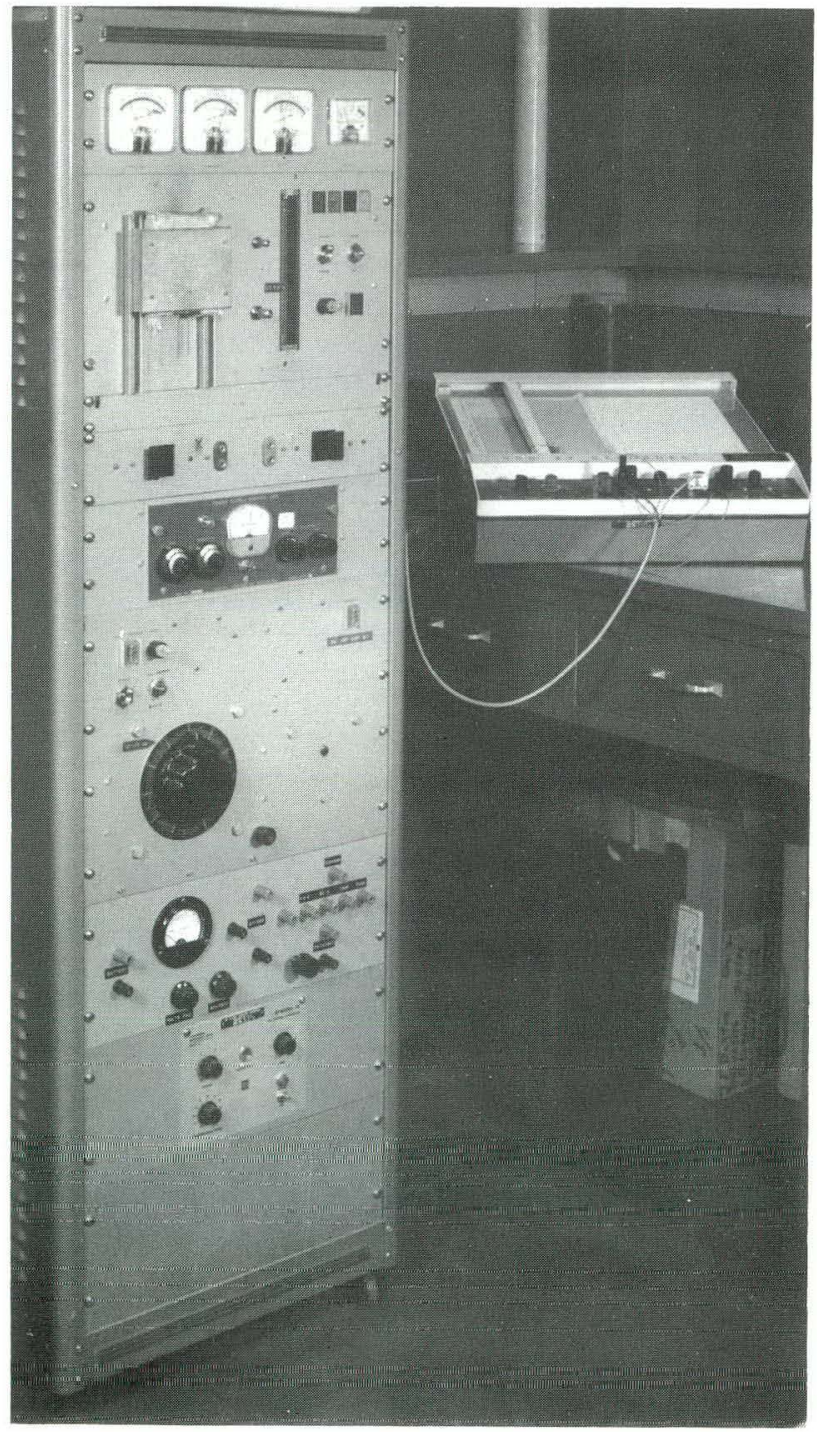

Figure 1: Pyrolysis Gas Evolution Analysis (PGEA) Apparatus

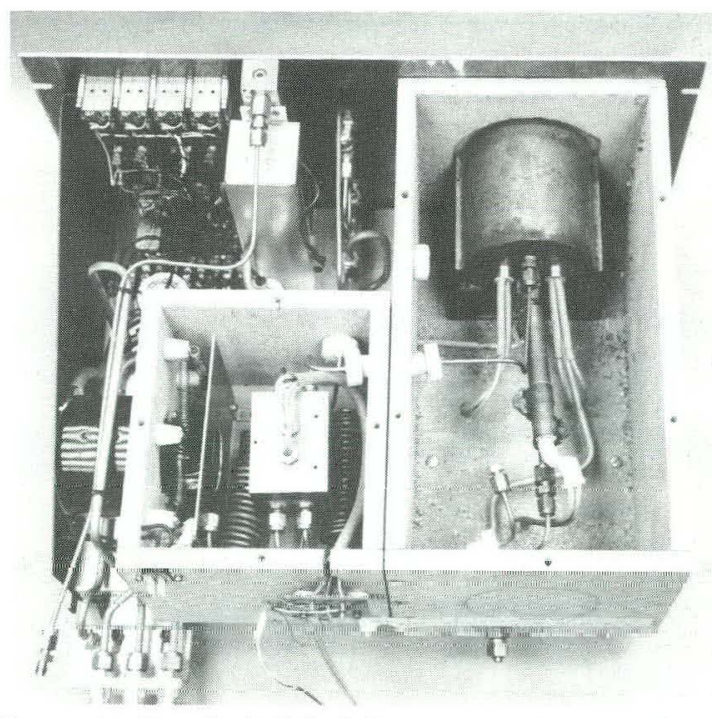

Figure 2: Pyrolysis Module Removed from Relay Rack. Control accessories are shown mounted compactly on uhassis. Left. Pleuun chamber (cover removed) shows heater, baffle, blower, coiled tubing and detector. Right: Chamber (cover and insulation removed) contains the pyrolysis block, combustor tube, thermocouples, and heaters. 


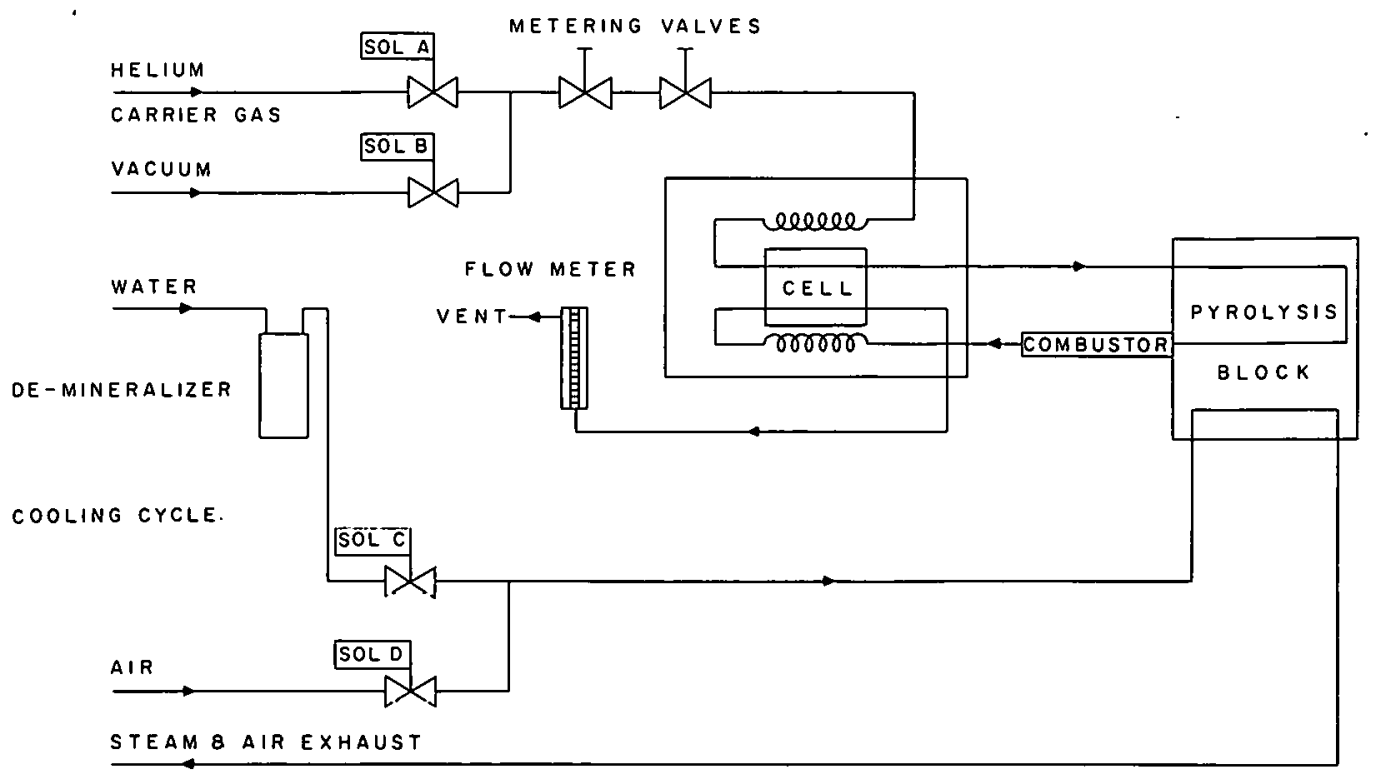

Figure 3: PGEA· Flow Schematic

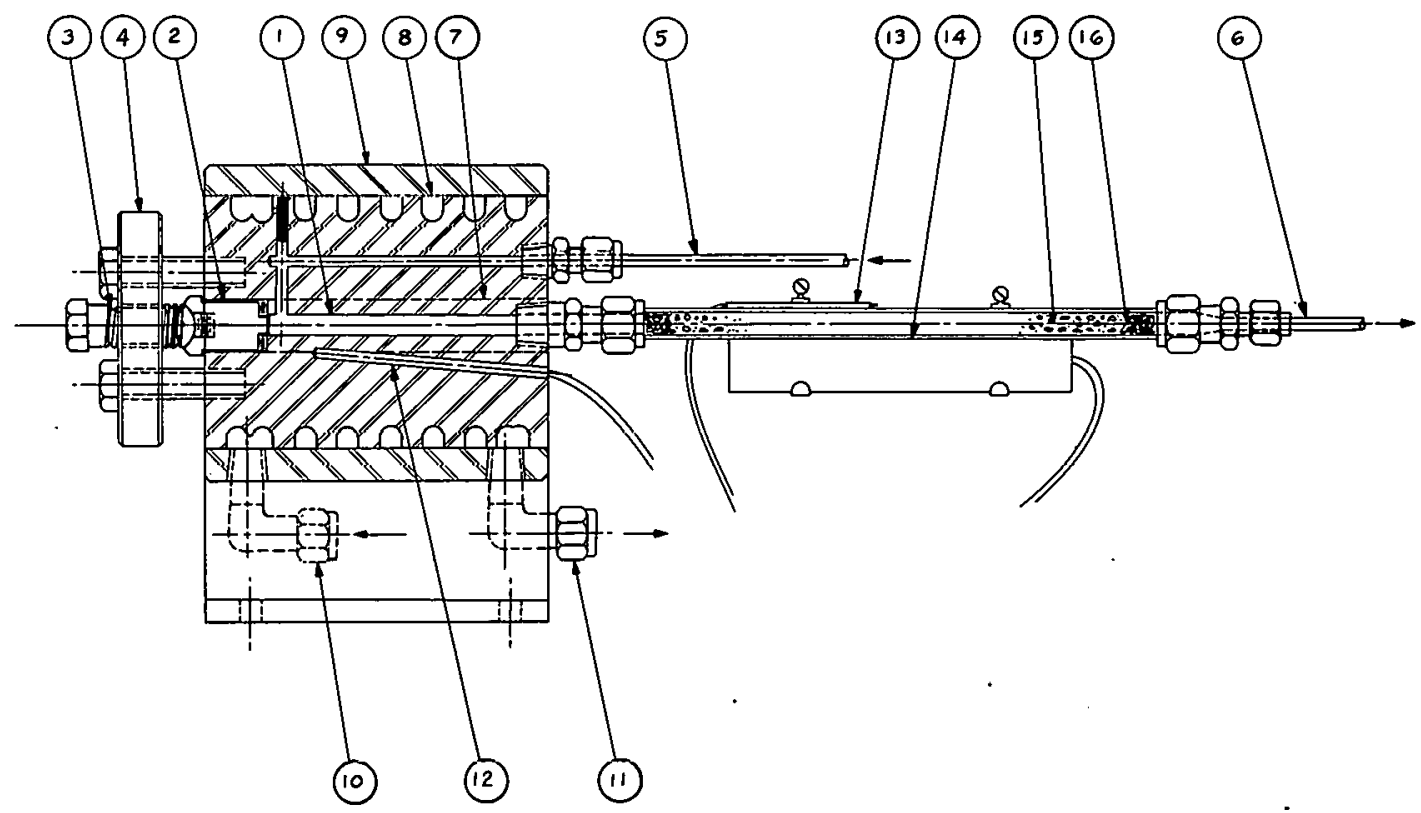

Figure 4: Pyrolysis Block and Combustor (cross sectional diagram)

1. Pyrolysis chamber

2. Stainless steel plug and gasket

3. Breech screw

4. Breech arm

5. Carrier gas inlet

from reference side of detector cell
6. Carrier gas outlet to sample side of detector cell

7. Cartridge heater wells (2)

8. Helical threads cut in block for cooling water

9. Outer shell of block
10. Cooling water jacket inlet

11. Cooling water jacket outlet

12. Ceramic sheathed thermocouples in block well

13. Ceramic sheathed thermocouples on combustor tube

14. Cartridge heater clamped on tube

15. Cupric oxide and quartz chips packed in

combustor tube

16. Quartz wool plug 


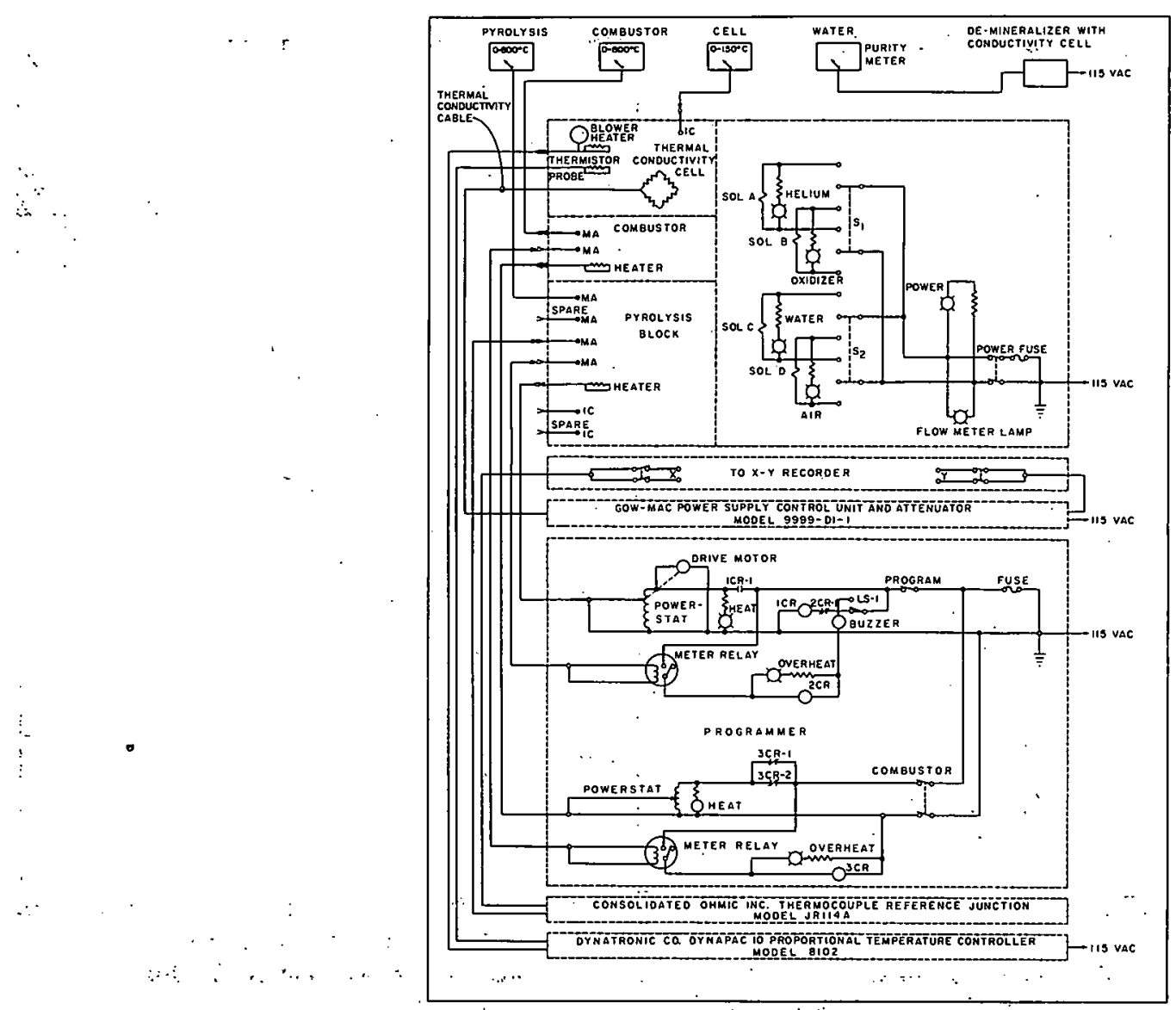

Figure 5: PGEA Electrical Schematic

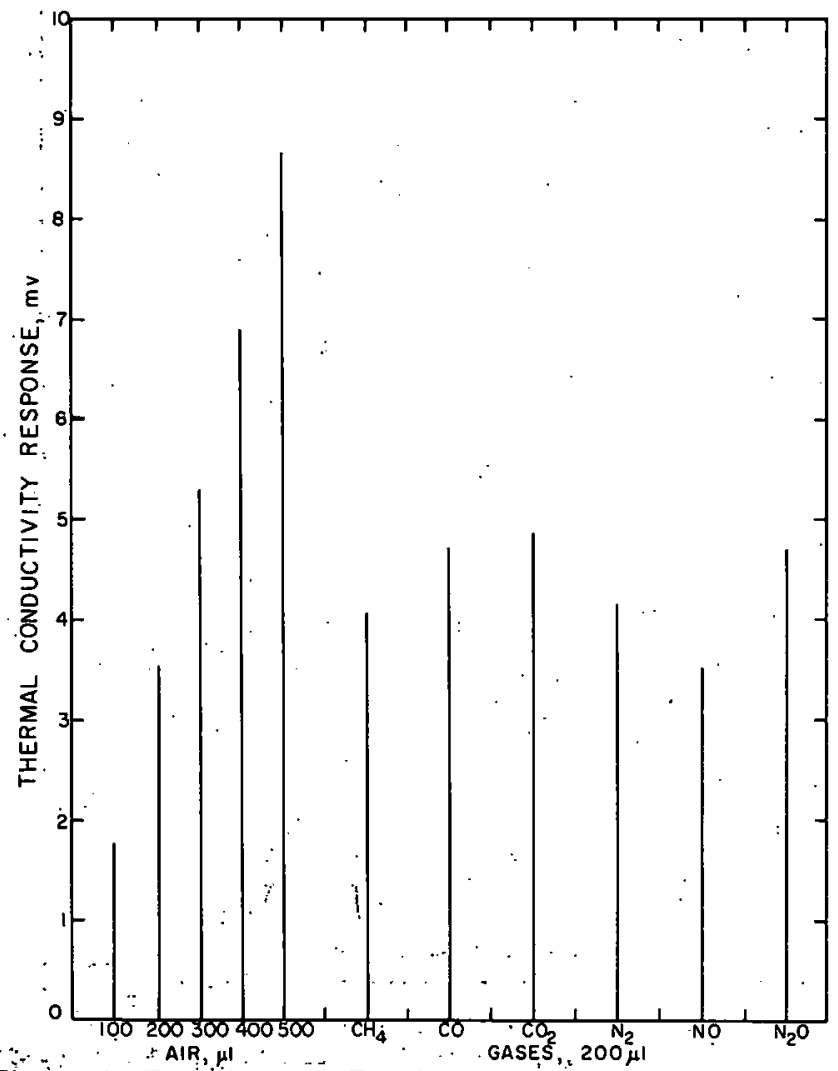

Figure 6: Programmed Pyrolysis Block: Temperature Versus Elapsed Time $\quad$ F\&M Programmer, $21^{\circ} \mathrm{C} / \mathrm{min}$ Curve A. F\&M Programmer, $21^{\circ} \mathrm{C} / \mathrm{m}$
B. Fixed Rate Programmer, B. Fixed Rate $12^{\circ} \mathrm{C} / \mathrm{min}$

C. F\&M Programmer, $1^{\circ} \mathrm{C} / \mathrm{min}$

D. F\&M. Programmer, $6^{\circ} \mathrm{C} / \mathrm{min}$

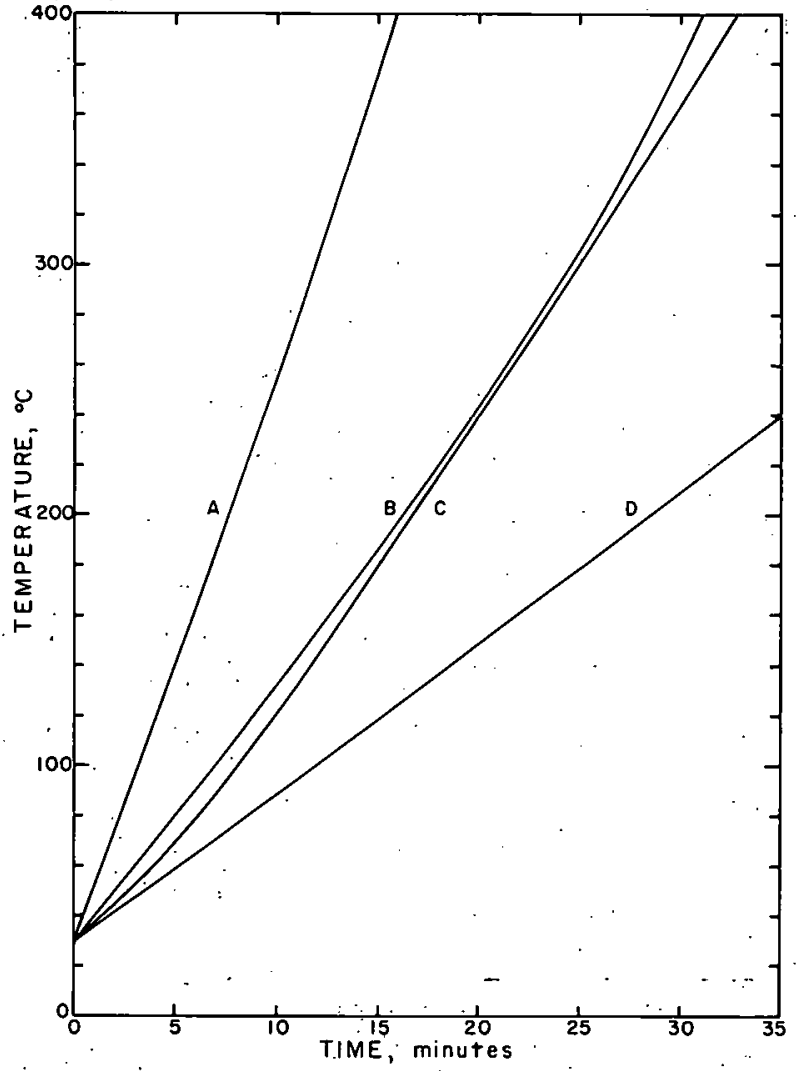

Figure 7: Peak Heights of Different Volumes of Air and of Equal Volumes of Several Gases. At constant conditions of temperature, pressure, and flow. 


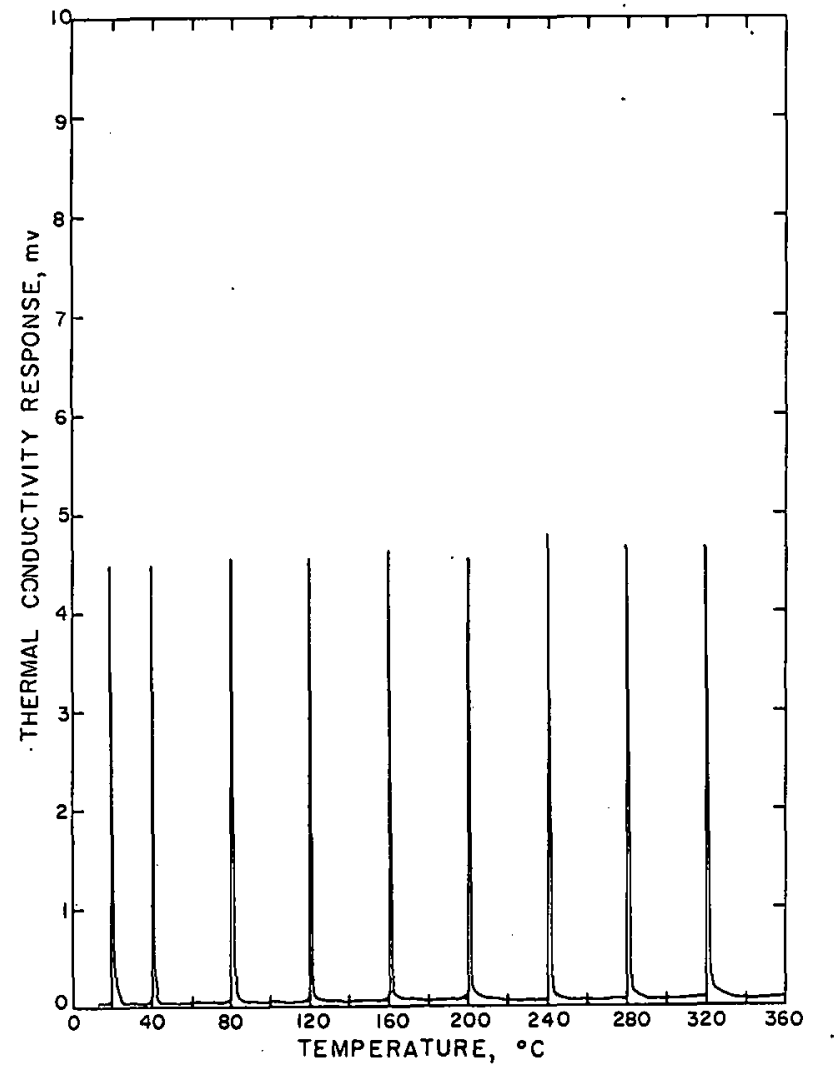

Figure 8: Peak Heights of Constant Volumes of Air Injected as the Apparatus Was Being Programmed

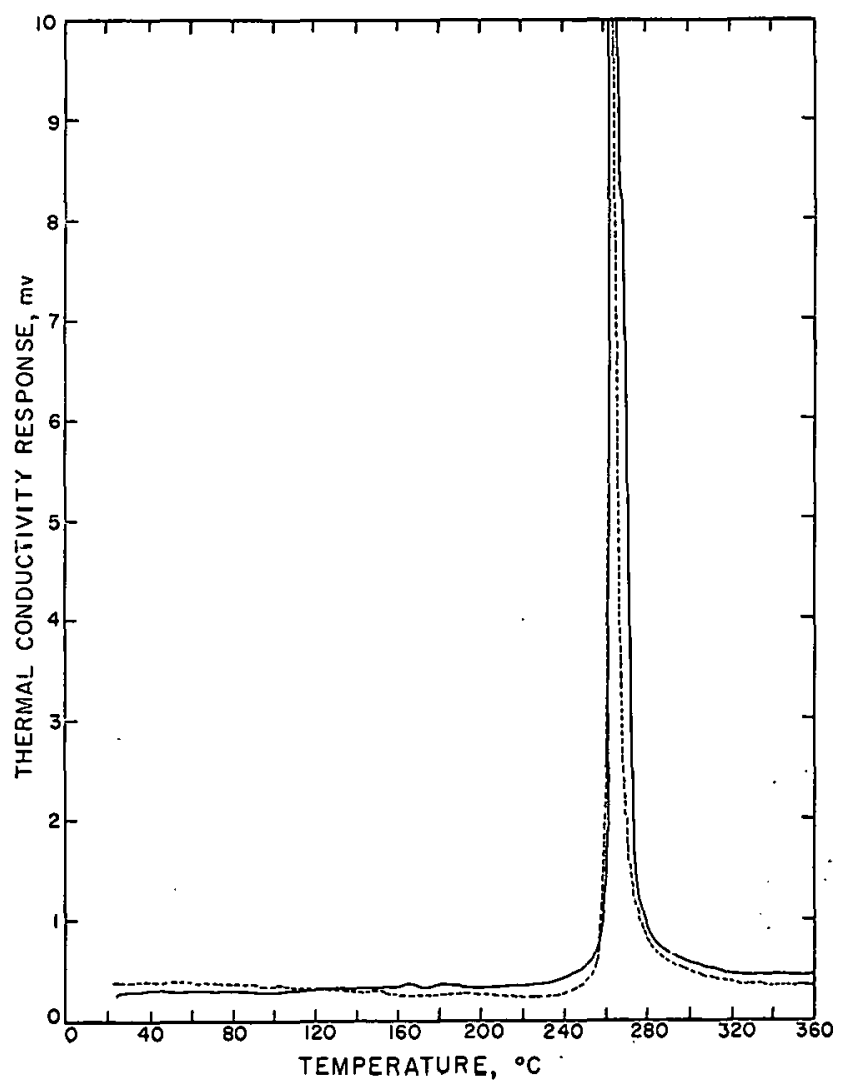

Figure 10: Pyrolysis Curves of HMX (99.5\% purity, United Kingdom). Comparison of GMX-2 (dashed line) curve with GMX-3 curve.

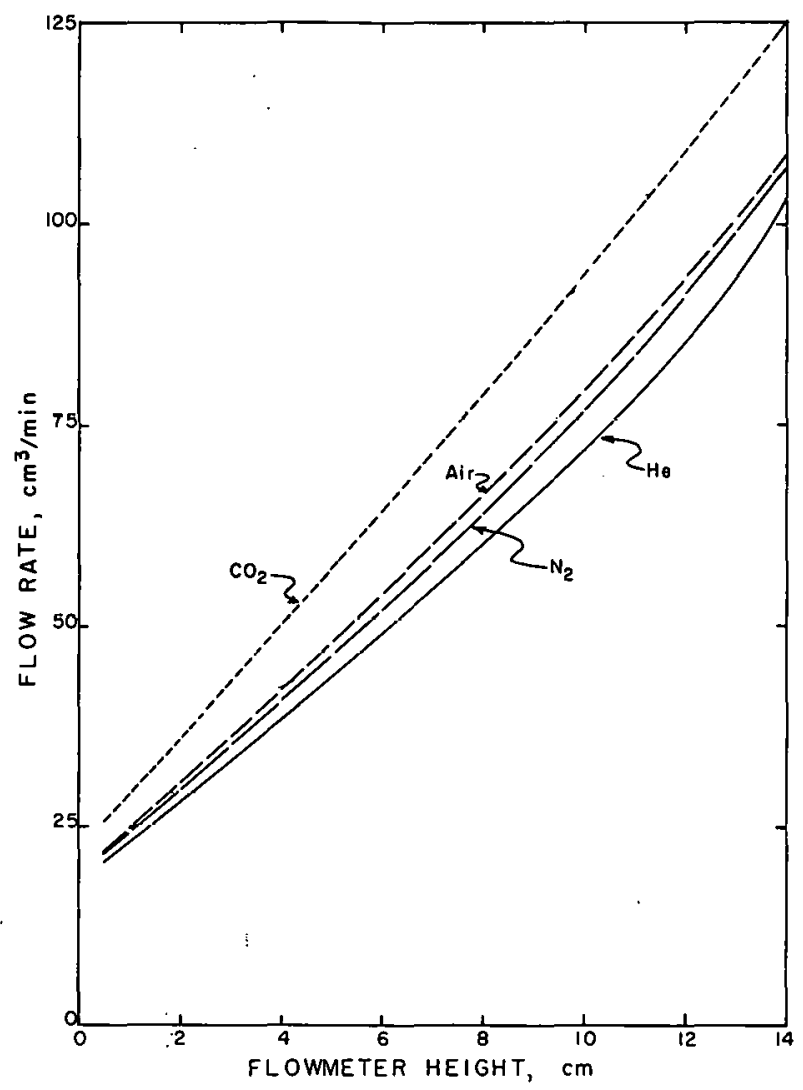

Figure 9: Flow Rate Versus Flowmeter Setting

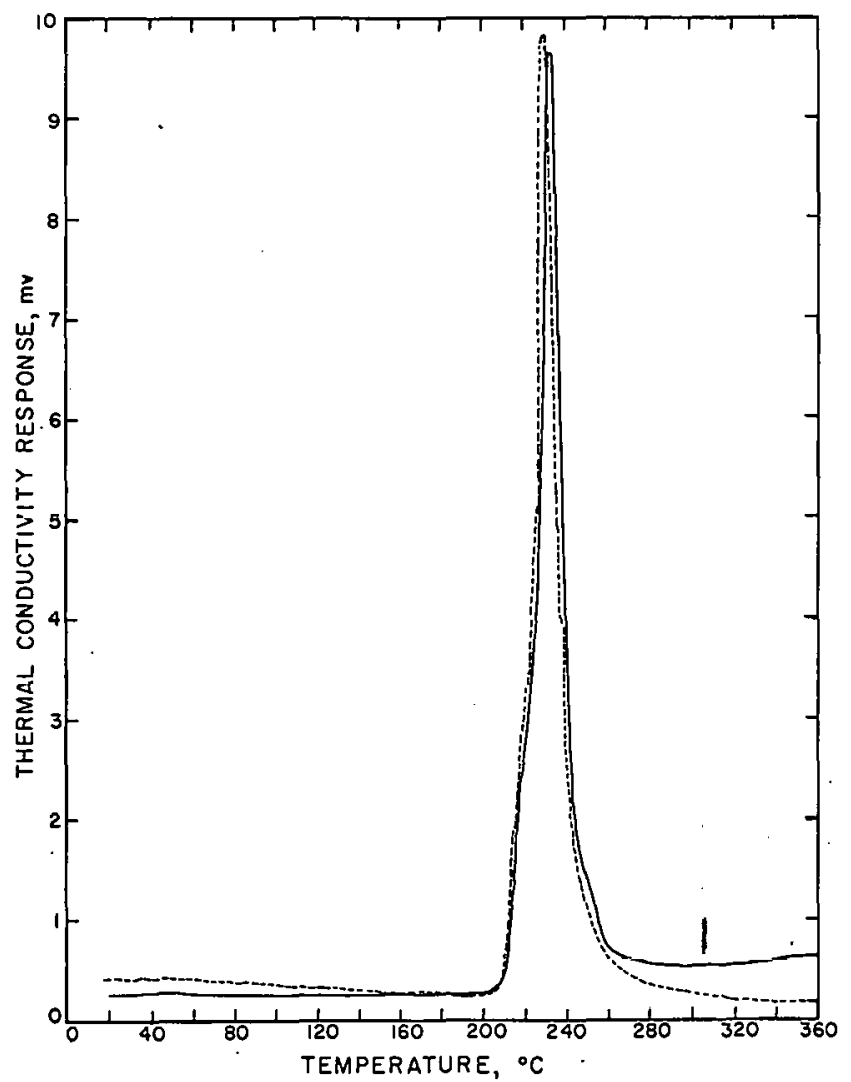

Figure 11: Pyrolysis Curves of Nitroguanidine (NQ), DMF Recrystallized - Lot 62-066-2-1. Comparison of GMX-2 (dashed line) curve with GMX-3 curve. 


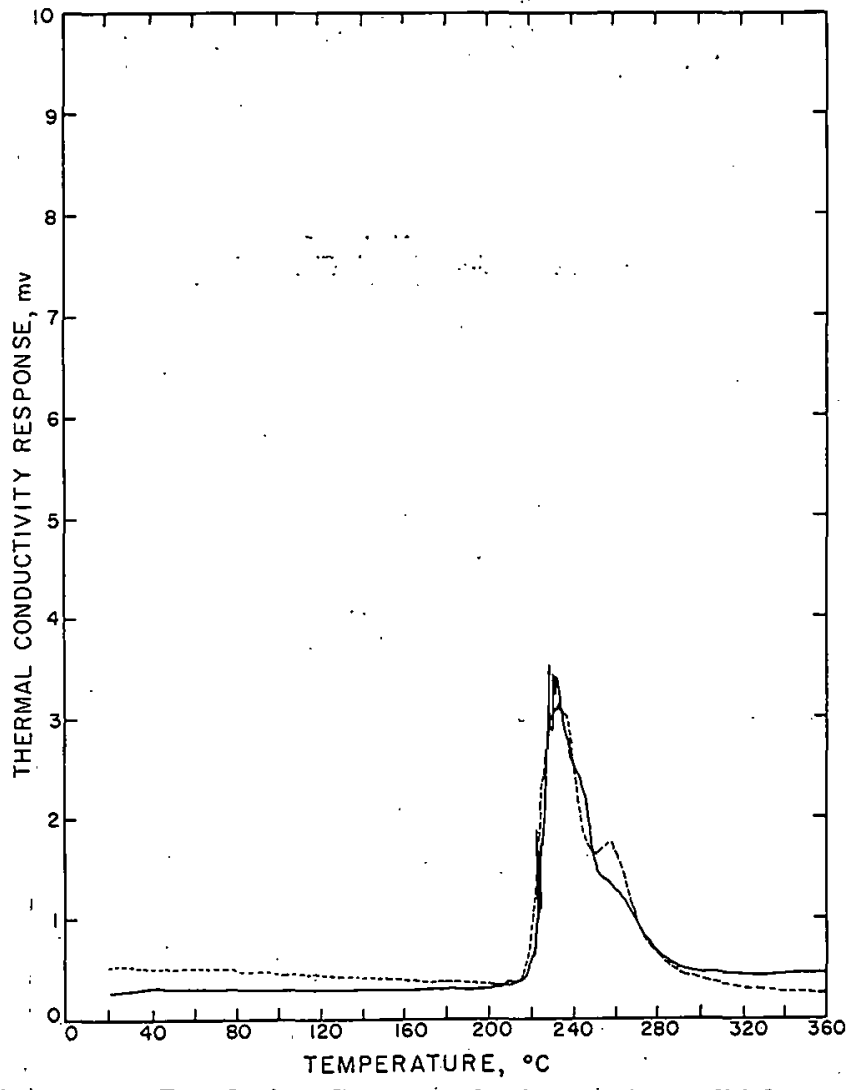

Figúre 12. Pyrolysis Curves of " Ammonium .Dichromate, $\left(\mathrm{NH}_{4}\right)$ Cr.O : Fisher analytical reagent A-644, Comparison of GMX-2 (dashed line) curve with GMX-3 curve.

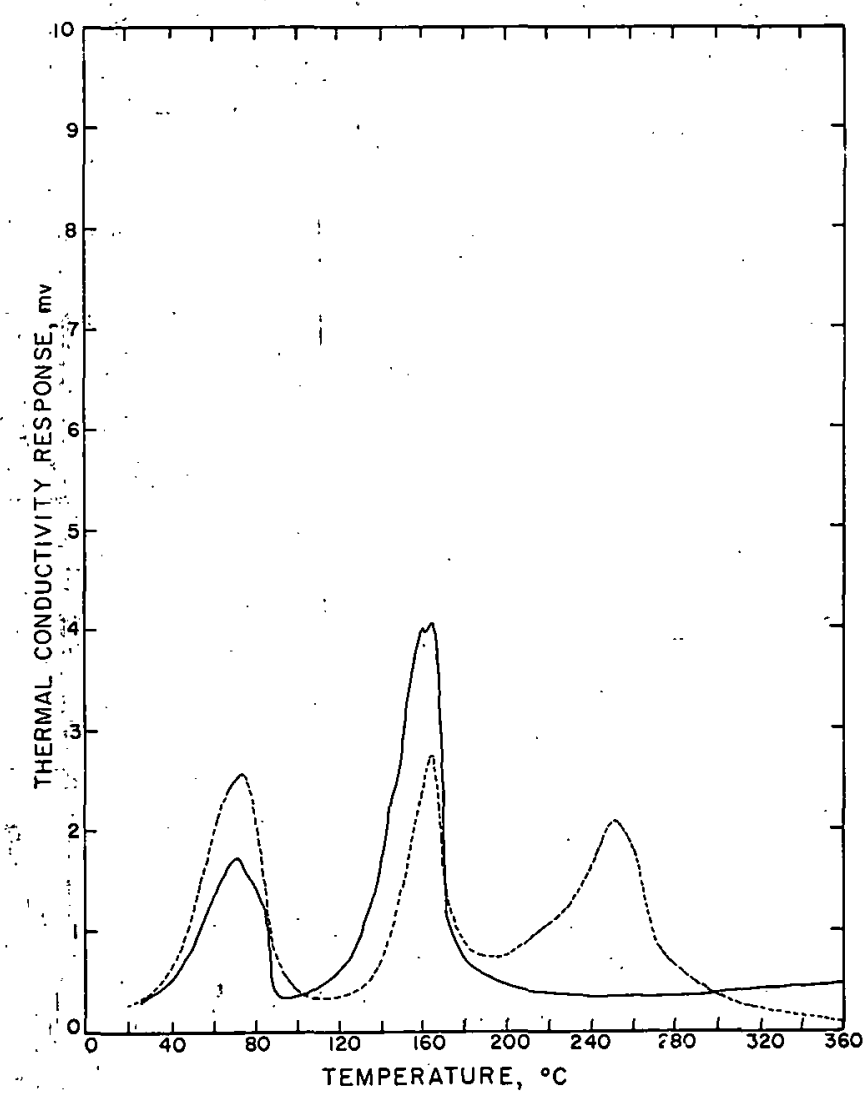

Figure 14: Pyrolysis Curves of Oxalic Acid, Dihydrate, C.H.O . 2H.O - GMX-2 analytical reagent. Comparison of GMX-2 (dashed line) curve with GMX-3 curve.

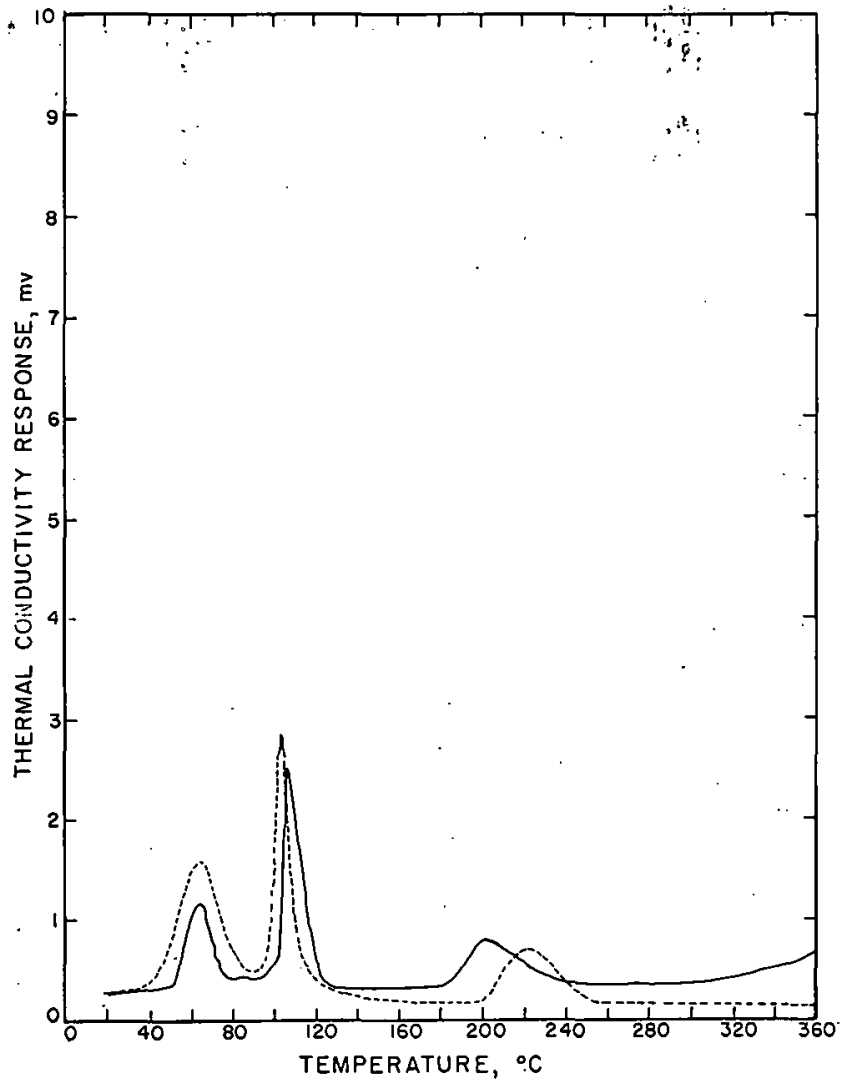

Figure 13: Pyrolysis Curves of Cupric Sulfate, Pentahydrate, $\mathrm{CuSO}_{4}$ : 5H.O - Baker's analytical reagent. Comparison of GMX-2 (dashed line) curve with GMX-3 curve. Broad peaks show water of hydration vaporizing.

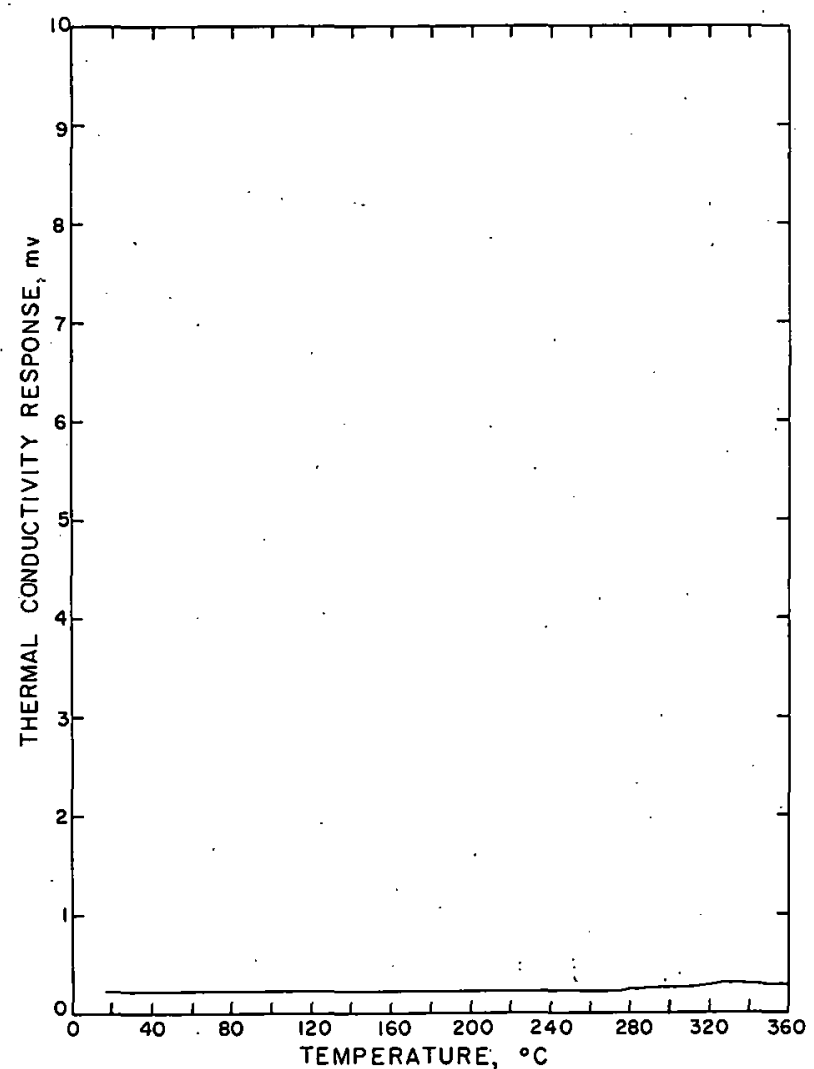

Figure 15: Base Line Curve. Programmed run without any sample in pyrolysis block. 


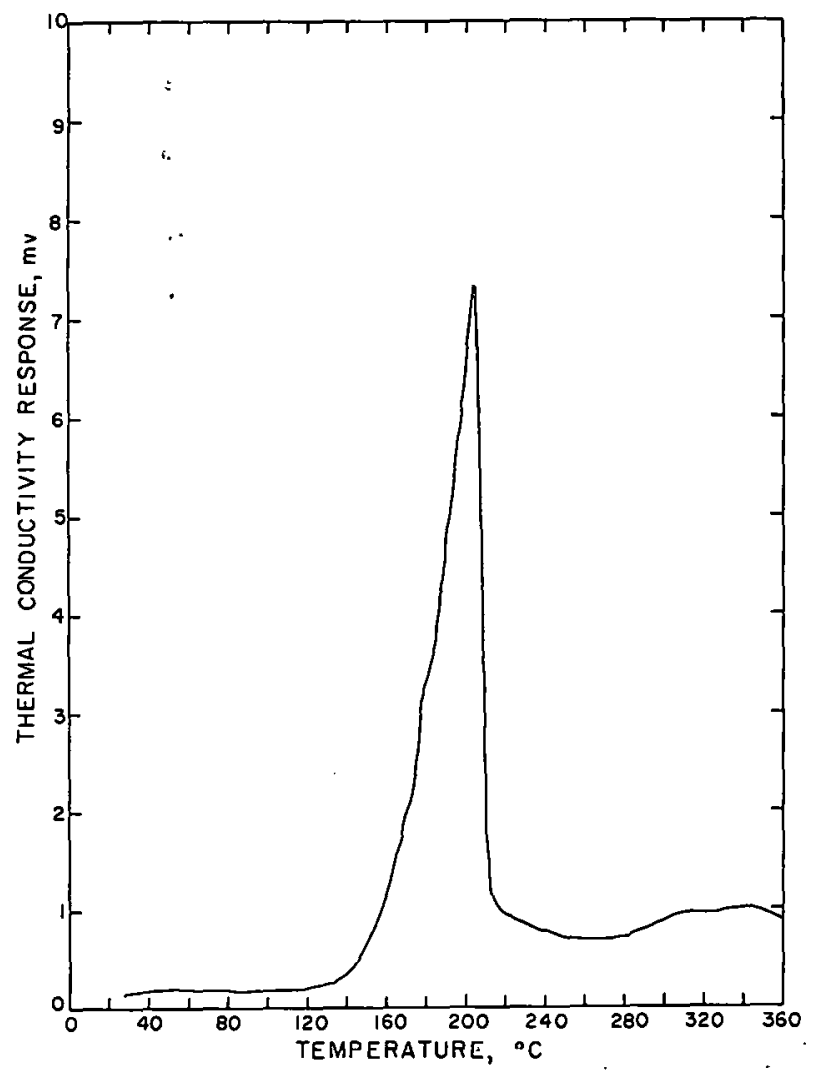

Figure 16: Pyrolysis Curve of Analytical Reference Sample of TNT - Lot WLG-3083

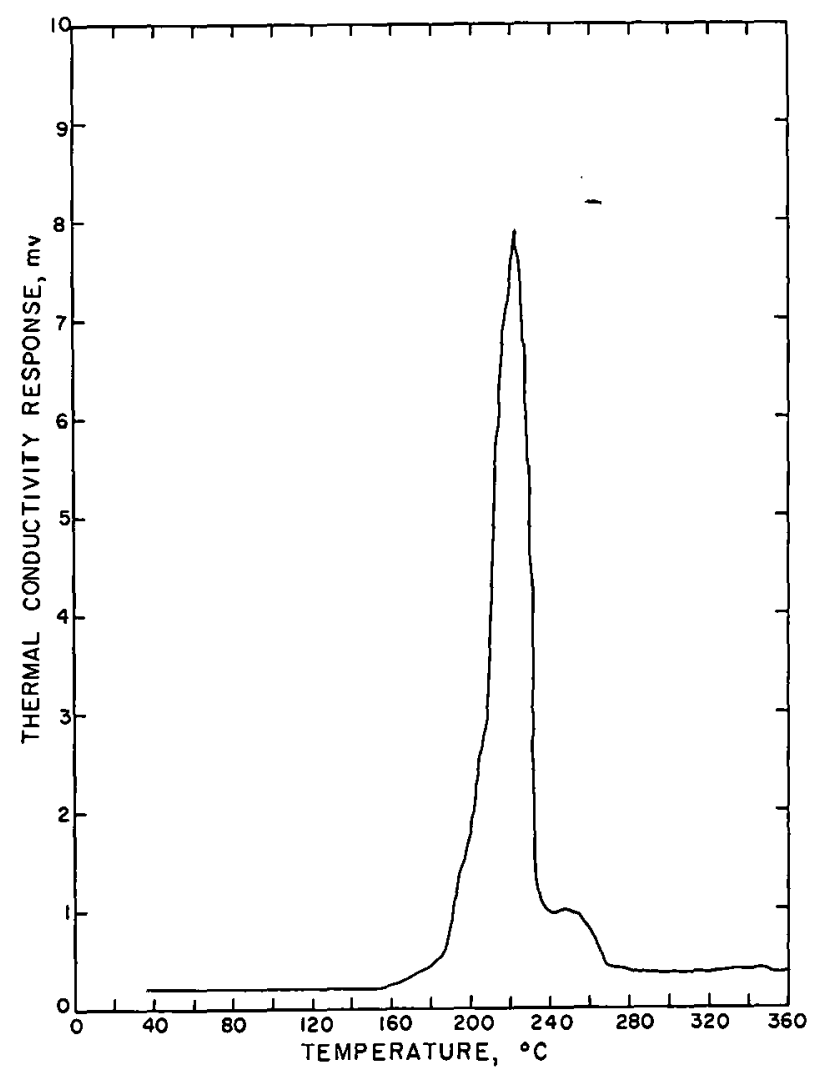

Figure 18: Pyrolysis Curve of Analytical Reference Sample of RDX - Lot Holston 39-57

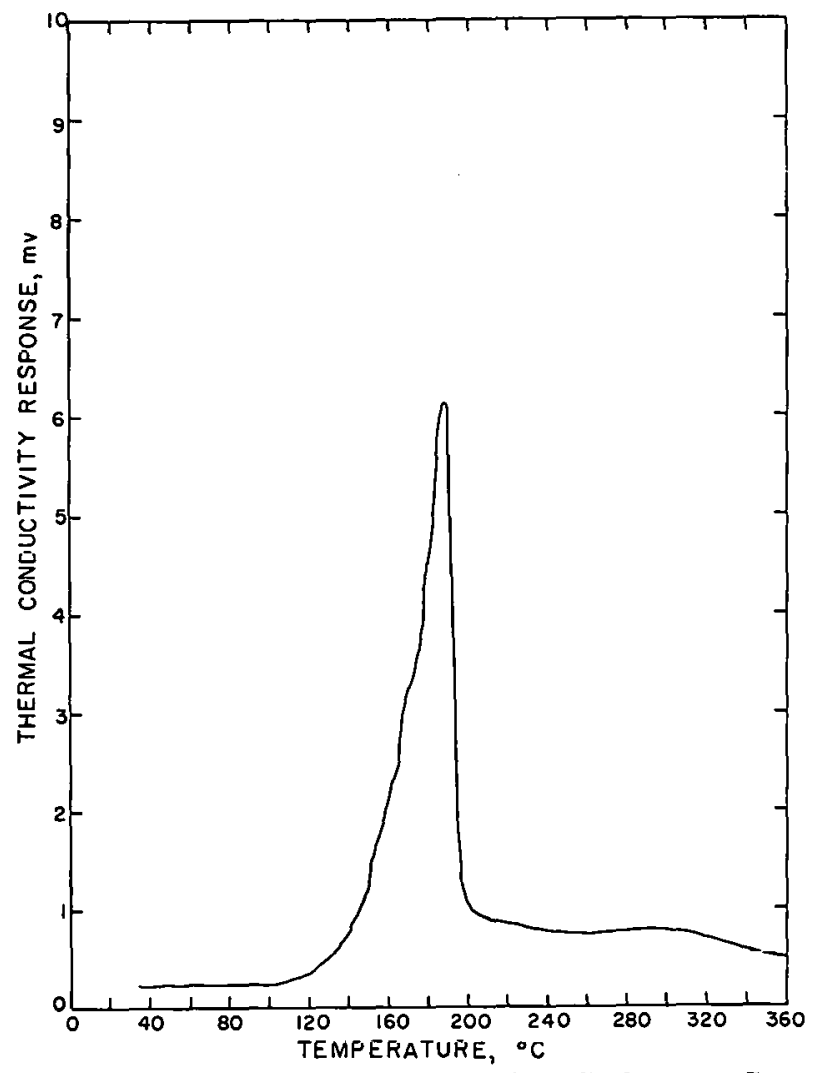

Figure 17: Pyrolysis Curve of Analytical Reference Sample of TNT Flake - Lot Vol 1-2177

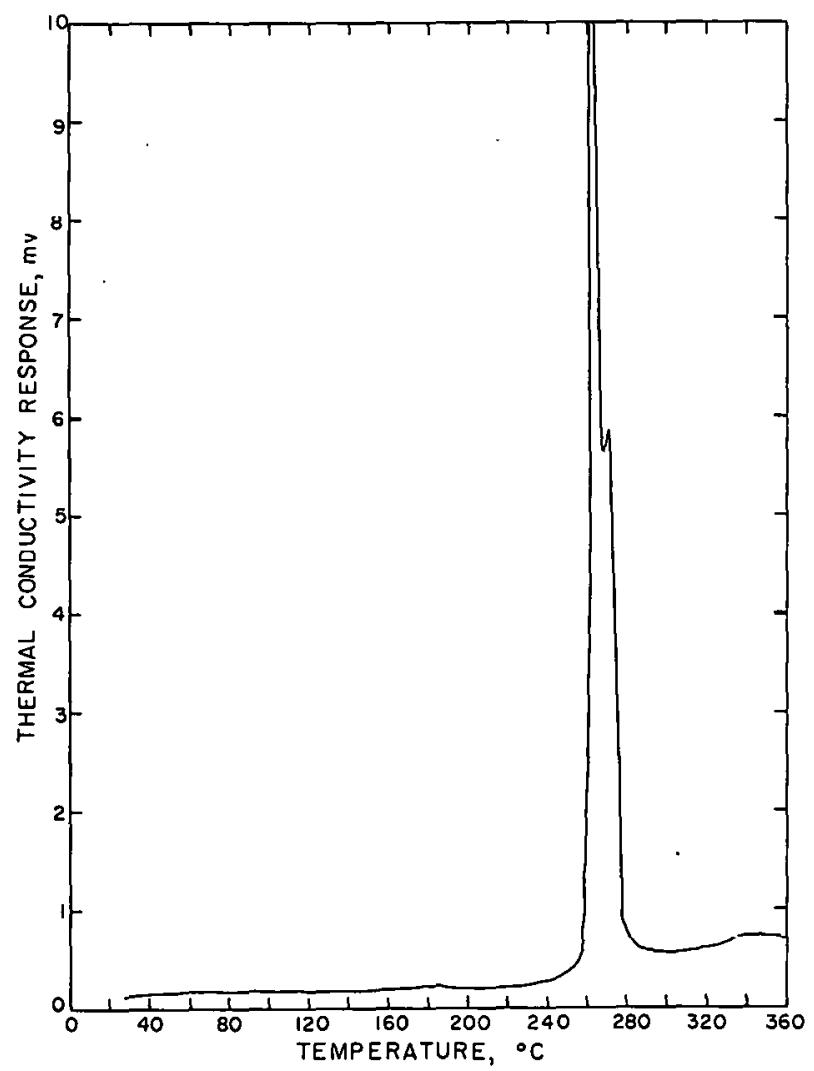

Figure 19: Pyrolysis Curve of Analytical Reference Sample of HMX - Lot UK, BGW-14, Q528 


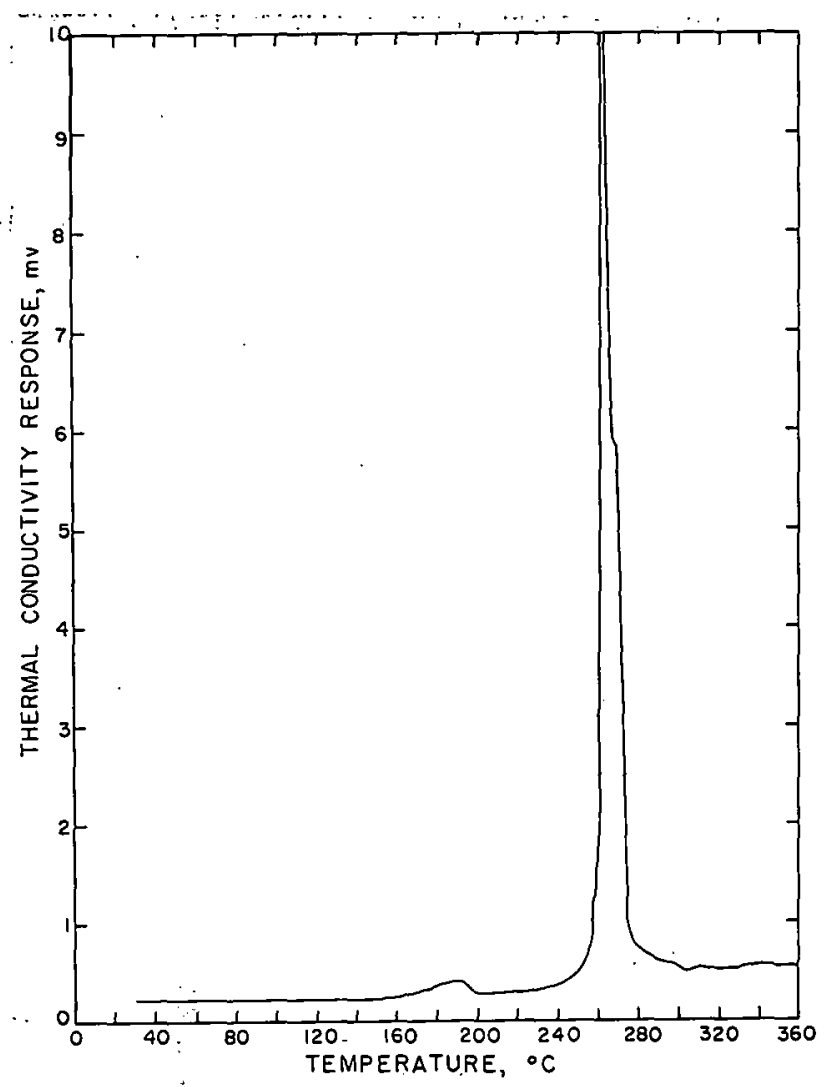

Figure 20: Pyrolysis Curve of Analytical Reference Sample of HMX - Lot Holston SR-79-58 BC-18

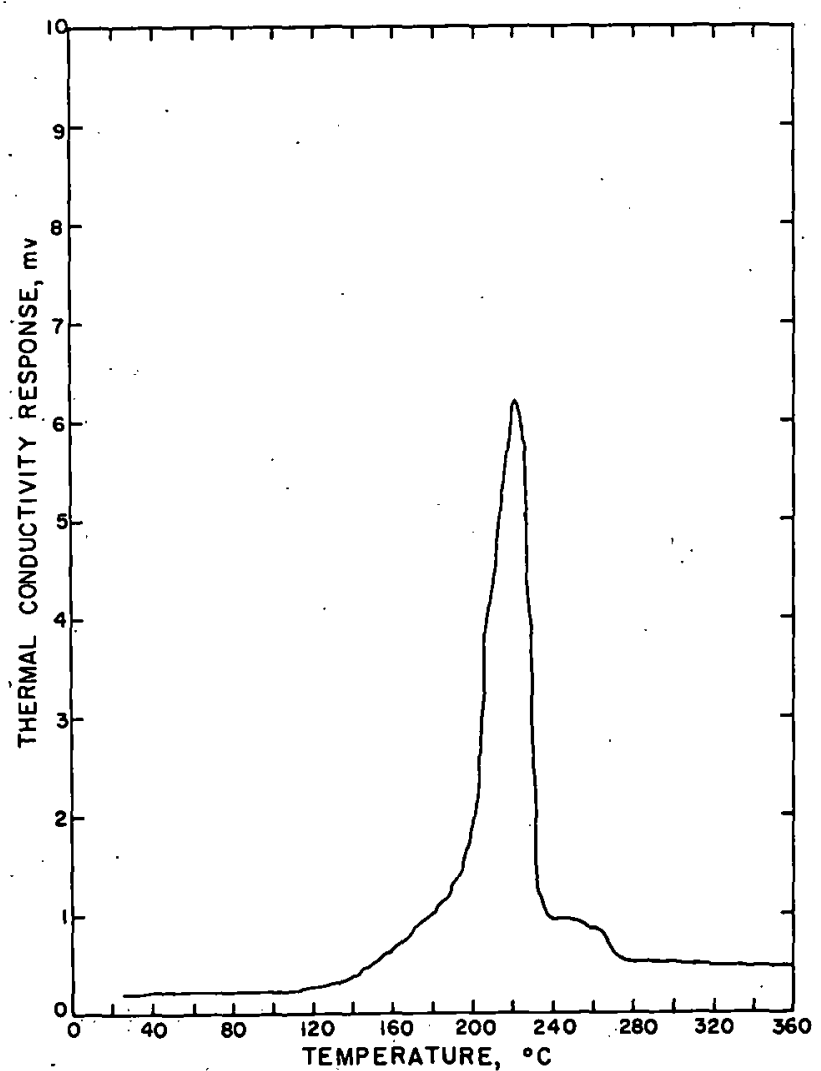

Figure 22: Pyrolysis Curve of Analytical Reference Sample of Cyclotol - Lot 6-114

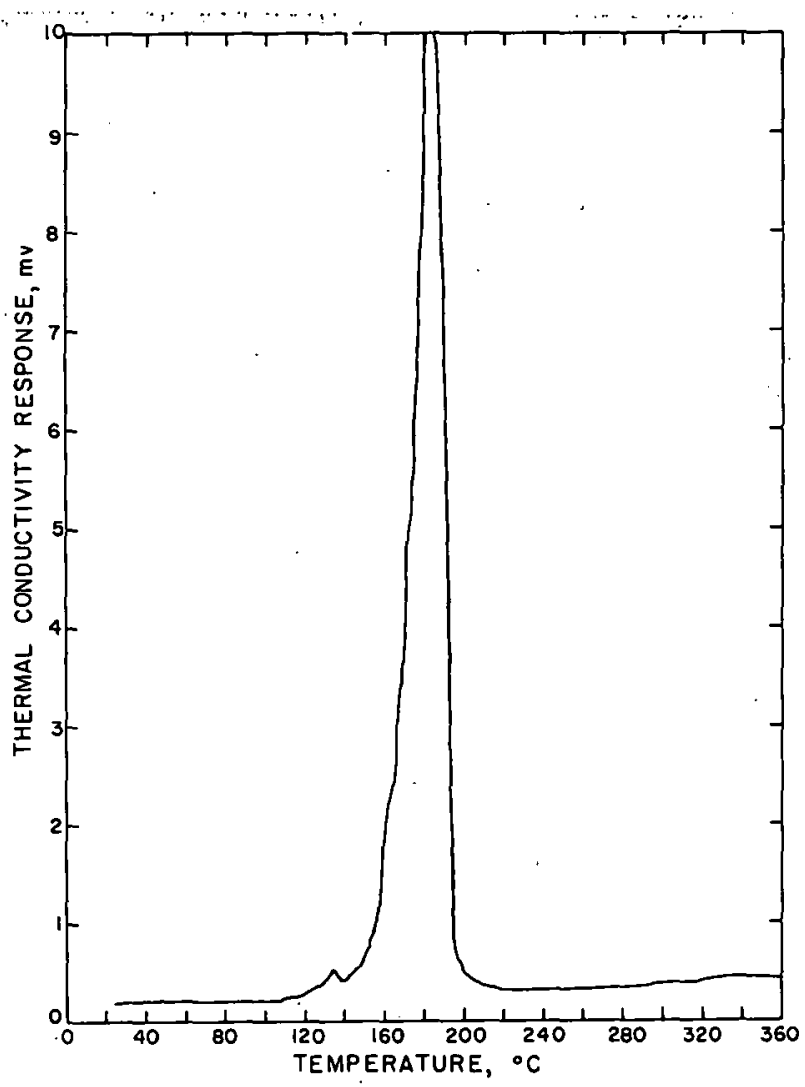

Figure 21: Pyrolysis Curve of Analytical Reference Sample of PETN - Lot Du Pont Superfine, 12-9

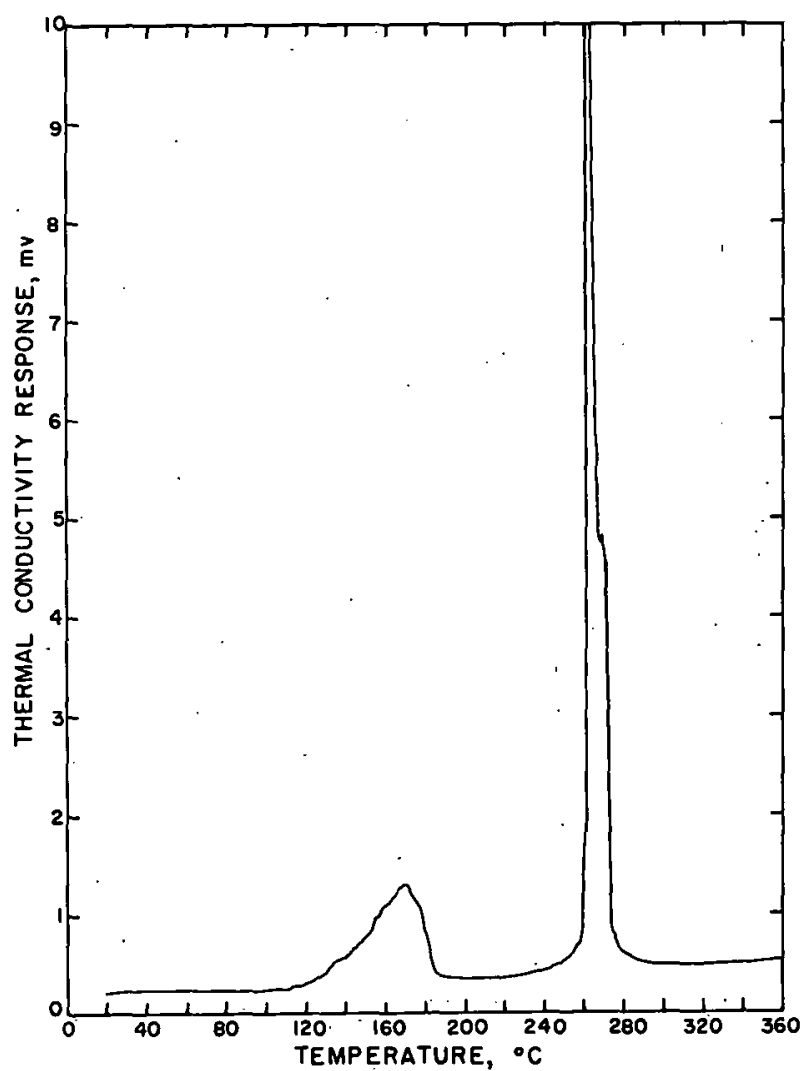

Figure 23: Pyrolysis Curve of Analytical Reference Sample of Octol -.Lot Holston SR-78-63. 


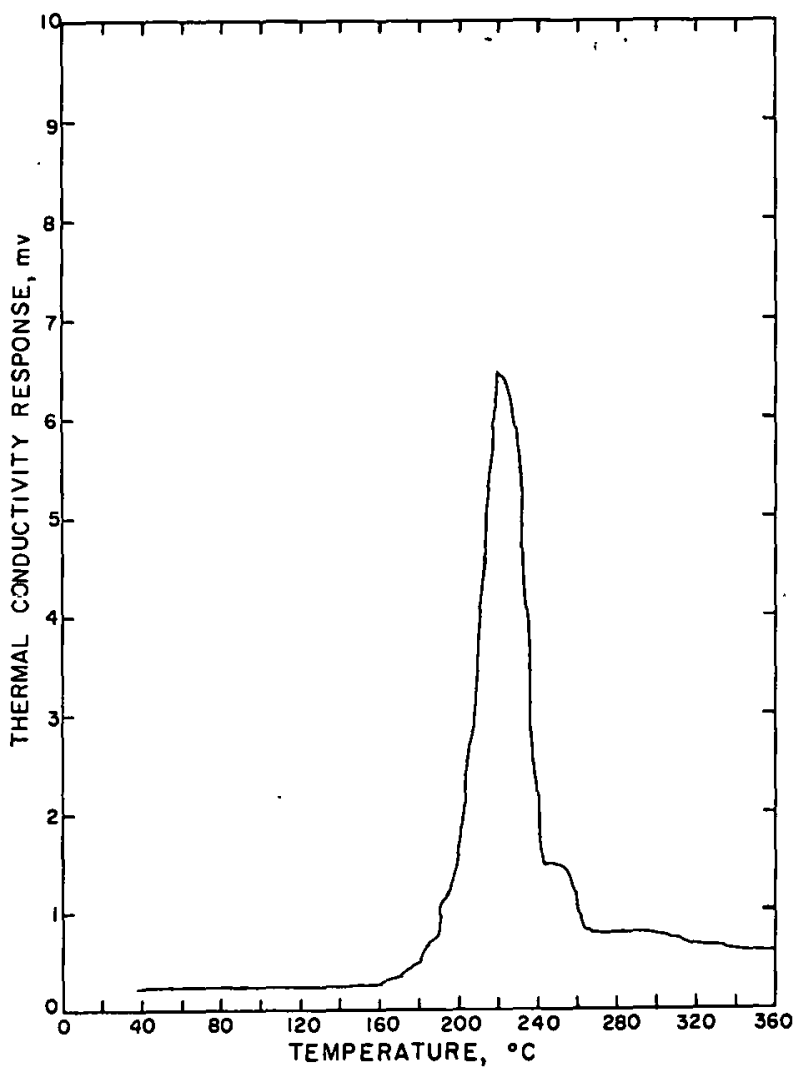

Figure 24: Pyrolysis Curve of Analytical Reference Sample of Composition A-3 - Lot Holston 1-13

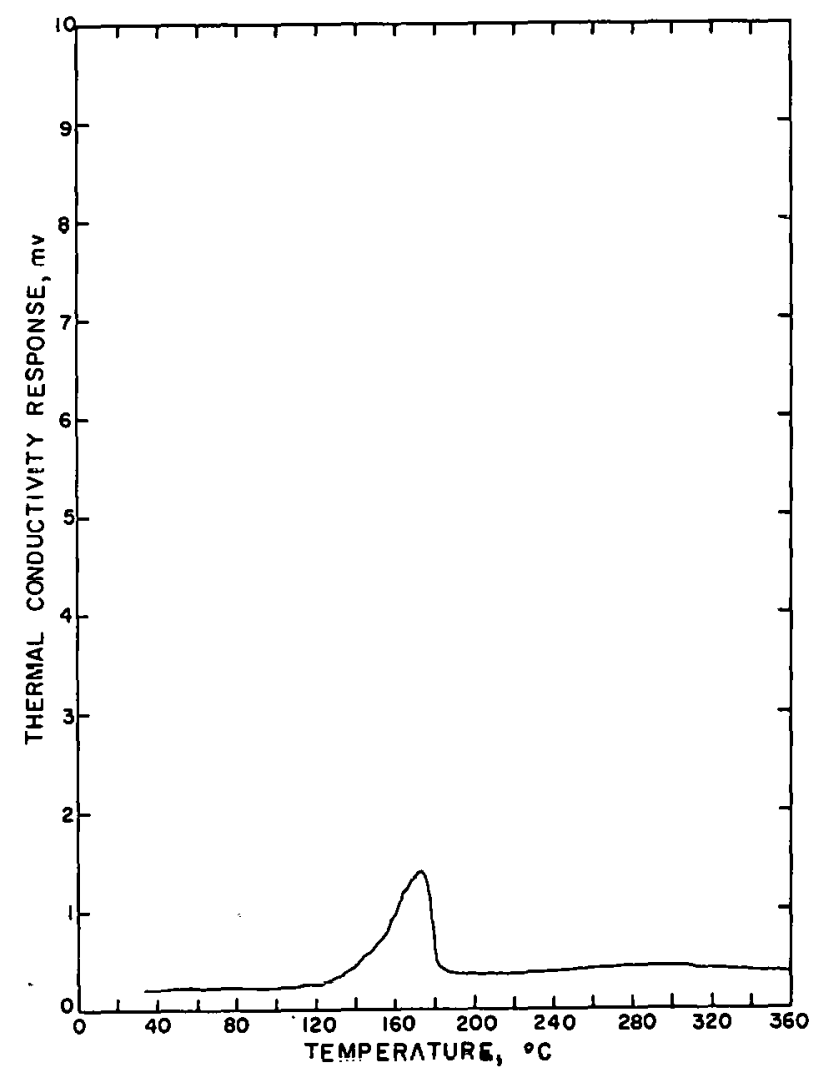

Figure 26: Pyrolysis Curve of Analytical Reference Sample of Baratol - Lot 7631-26

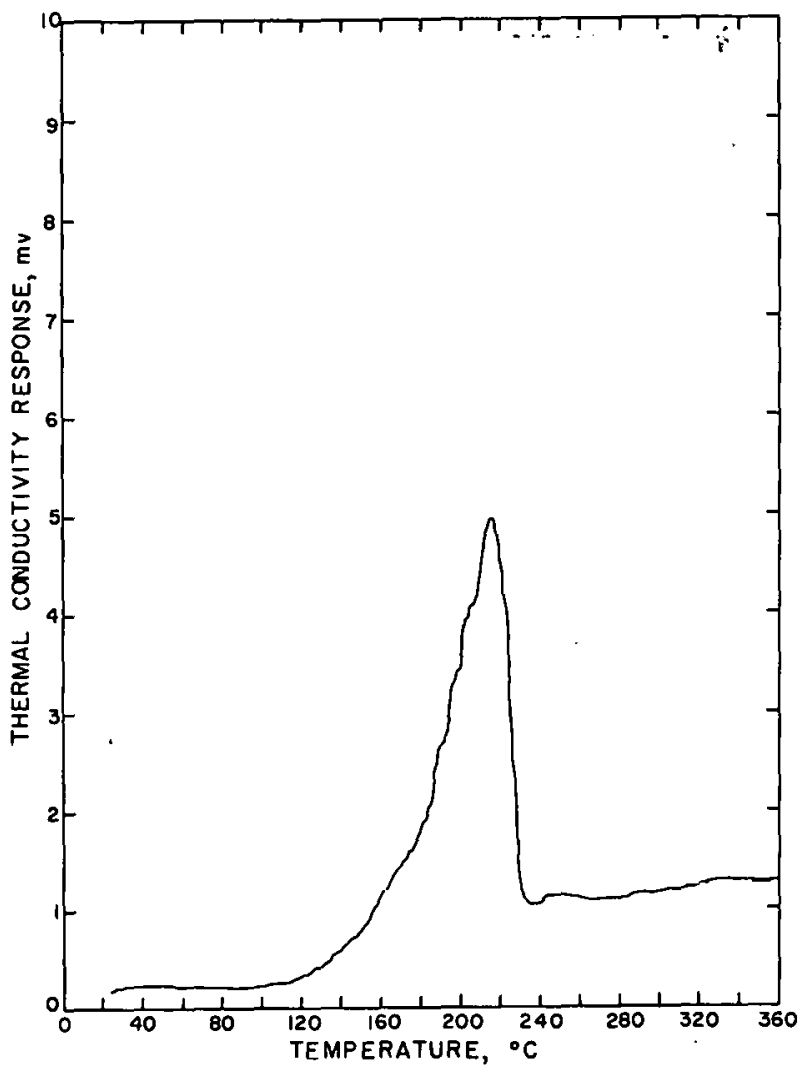

Figure 25: Pyrolysis Curve of Analytical Reference Sample of Composition B-3 - Lot Holston 11-86

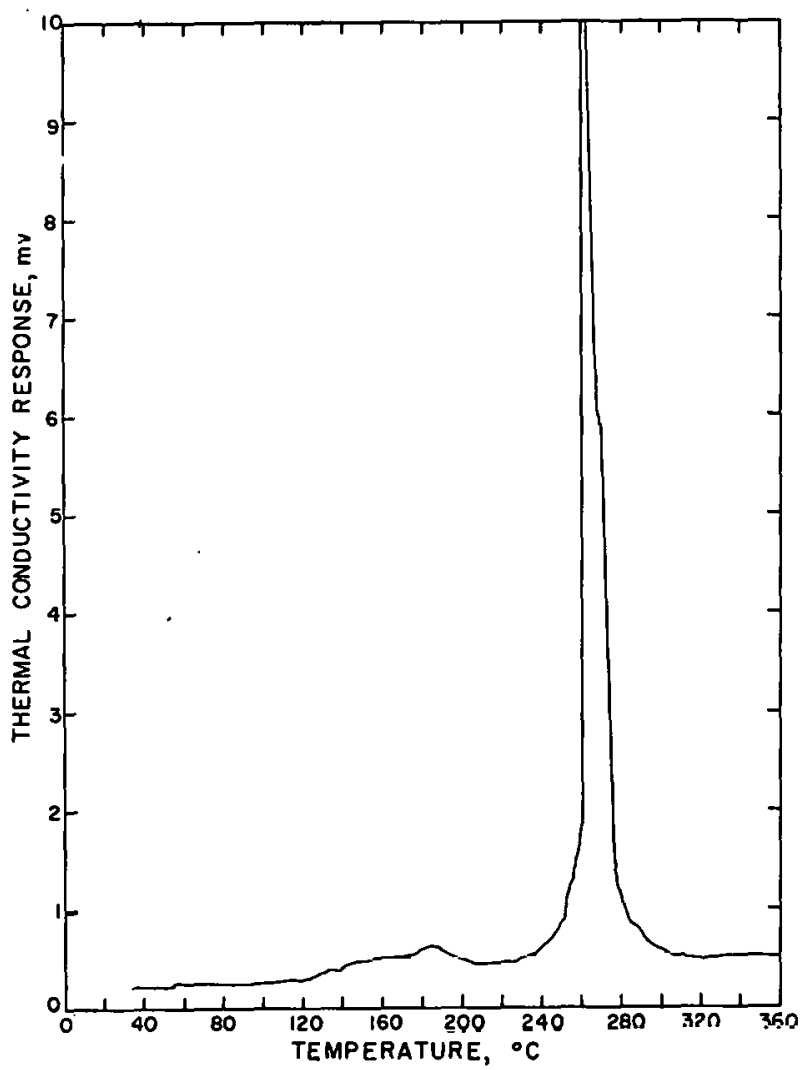

Figure 27: Pyrolys̄is Curve of Analytical Reference Sample of PBX 9404-03 - Lot 24 


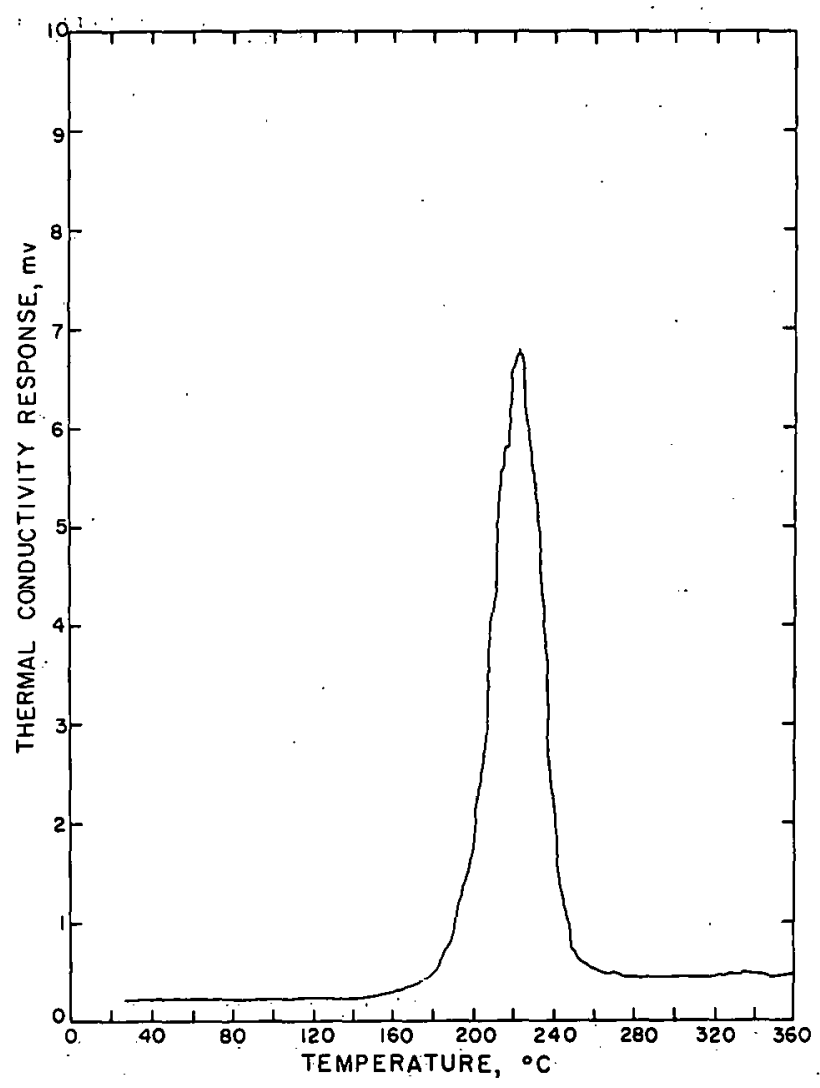

Figure 28: Pyrolysis Curve of. Analytical Reference Sample of PBX 9010-02 - Lot 492-61

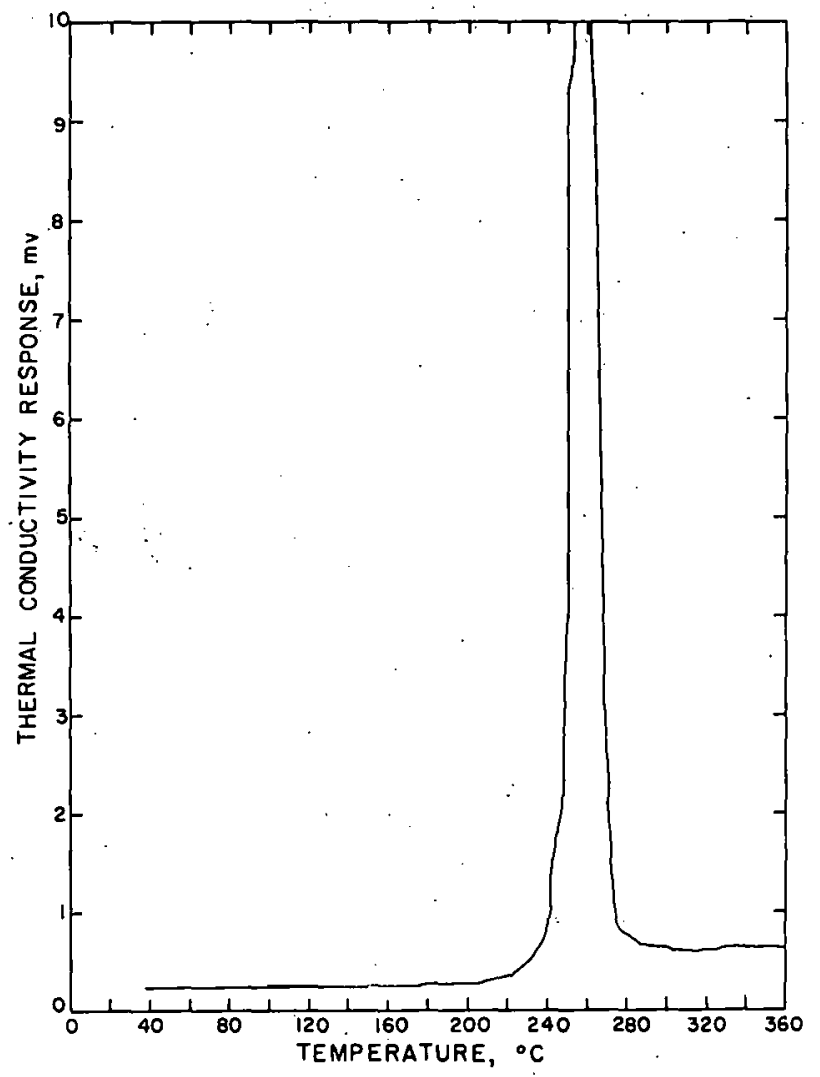

Figure 29: Pyrolysis Curve of Analytical Reference Sample of PBX 9011 - Lot 1073

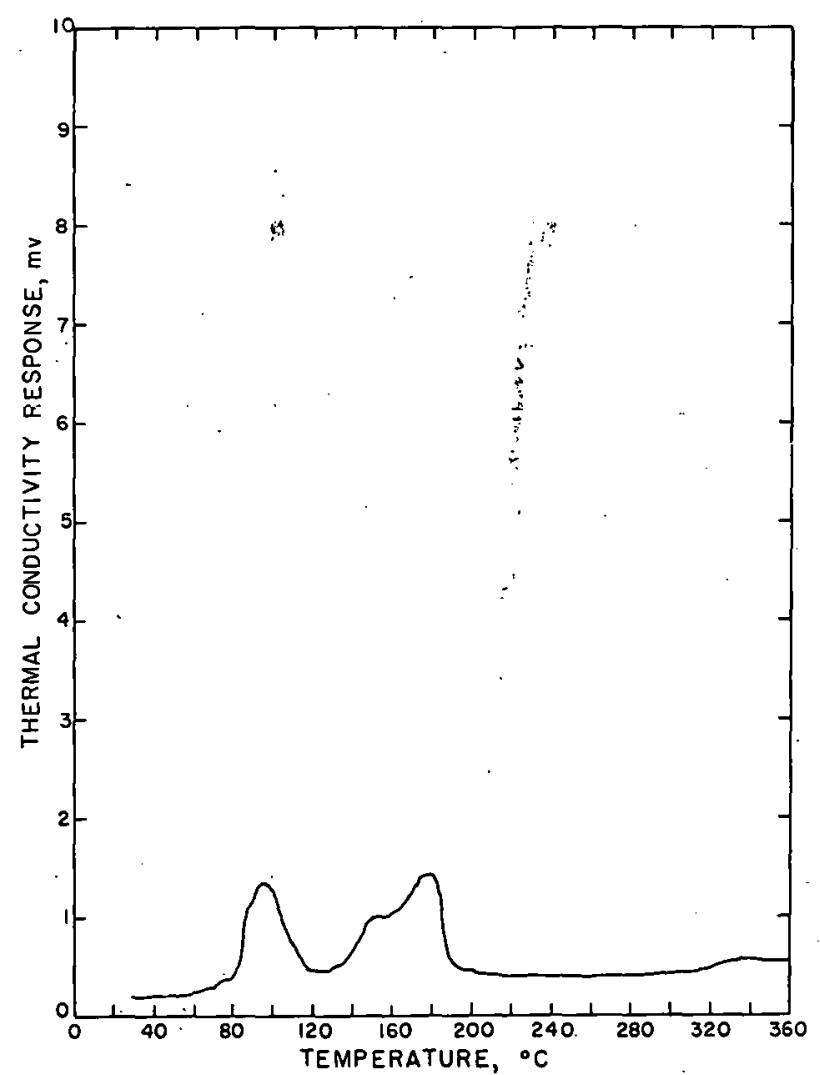

Figure 30: Pyrolysis Curve of Analytical Reference Sample of Boracitol - Lot P64 